\title{
DIFERENCIAIS SALARIAIS PARA O SETOR CULTURAL E OCUPAÇÕES ARTÍSTICAS NO BRASIL
}

\author{
Amir Borges Ferreira Neto* \\ Ricardo da Silva Freguglia ${ }^{\dagger}$ \\ Bernardo de Abreu Guelber Fajardo ${ }^{\ddagger}$
}

\begin{abstract}
Resumo
Este artigo analisa o diferencial de salários dos trabalhadores do setor cultural e dos artistas no Brasil usando dados da Pesquisa Nacional por Amostra de Domicílios de 2002 a 2007. Para identificar os fatores que mais contribuem para as diferenças de remuneração foi utilizado o estimador de efeitos fixos em um modelo de pseudo painel de coortes, considerando a correção de viés de seleção através do procedimento de Heckman. Em geral, trabalhadores do setor cultural e artistas são melhores remunerados que os demais trabalhadores, notando-se a importância da correção do viés e dos controles de efeitos fixos de gerações. Por meio da decomposição de Oaxaca, o fator que mais contribui para as diferenças salariais é o de características setoriais.
\end{abstract}

Palavras-chave: Diferenciais Salariais; Economia da Cultura; Viés de Seleção; Decomposição de Oaxaca.

\begin{abstract}
This paper analyses the wage differentials among workers from the cultural sector and the artists in Brazil using data from PNAD - a household survey conducted by the Brazilian Statistics Bureau (IBGE) - from 2002 to 2007. In order to identify the features that contribute to the differences we use the fixed effects estimator in a cohort pseudo panel model, paying attention to the correction of the selection bias using the Heckman's approach. In general, workers from the cultural sector and artists have higher wages than other workers. After correcting the selection bias and fixed effects, these differences are even higher. By the Oaxaca decomposition analysis, the cultural sector characteristics are the most important factor that generates these wage differences.
\end{abstract}

Keywords: Wage Differentials; Cultural Economics; Selection Bias; Oaxaca Decomposition.

JEL classification: J31, Z10

\footnotetext{
* PPGEA - Universidade Federal de Juiz de Fora. Email: amirneto@gmail.com.

† PPGEA - Universidade Federal de Juiz de Fora. Email: ricardo.freguglia@ufjf.edu.br.

‡ EBAPE/Fundação Getúlio Vargas. Email:bguelber@gmail.com
} 


\section{Introdução}

A economia da cultura é um termo muito abrangente e possui em seu conceito questões intangíveis, dessa forma não há uma definição unânime do que compõe seu estudo. Towse (2003) afirma que houve uma evolução no campo de estudos que antes incluía apenas as artes. Neste debate sobre a definição do objeto de estudo do campo de economia da cultura devem ser destacados os trabalhos de Markusen et al. (2008) e Cassiolato (2008), ambos dando enfoque à indústria criativa.

Throsby (2001), por sua vez, afirma que há duas formas de utilizar o termo cultura. A primeira é antropológica ou sociológica, que descreve as atitudes, crenças, morais, costumes, valores e práticas que são comuns ou divididos por um grupo, seja ele um grupo político, geográfico ou religioso. A segunda definição, que será utilizada neste trabalho, tem uma orientação mais funcional, denotando certas atividades que são empreendidas pelas pessoas, cujo produto está relacionado com os aspectos intelectual/criativo, moral e artístico da vida humana. Para ser mais preciso, o autor sugere três características ${ }^{1}$ para essas atividades: a) envolvimento de alguma forma de criatividade na sua produção; b) geração e comunicação de símbolos que façam sentido; c) existência de propriedade intelectual, ainda que de forma potencial, em seu produto.

Atualmente, as atividades culturais compõem um setor econômico estratégico, com participação de 7\% do PIB global em 2003, conforme estimativas do Banco Mundial. Não por acaso, as pesquisas internacionais sobre o tema vêm ganhando gradativamente mais espaço (Filer 1986, Blaug 2001, Benhamou 2003, Wetzels 2008). No Brasil, apesar do vasto potencial de geração de emprego e renda, assim como de bem-estar e capacitação do capital humano, essa discussão é ainda incipiente. Dentre os principais trabalhos da literatura nacional, destacam-se o de Bertini (2008), Reis $(2002,2006)$ e Valiati \& Florissi (2007), além das publicações do Ministério da Cultura (2007) 2 .

De modo semelhante às estatísticas mundiais, o setor cultural brasileiro também se destaca por sua importância econômica. Segundo os dados do IBGE (2005), cerca de 5\% das pessoas ocupadas e aproximadamente $11 \%$ do PIB estão alocados na chamada indústria da cultura. Fundação João Pinheiro - FJP (1998) destaca que os trabalhadores do setor cultural são 30\% mais bem remunerados que o do setor não cultural e que o setor crescia a taxas superiores que o restante da economia.

O mercado de trabalho do setor cultural é de alguma forma, distinto dos mercados tradicionais (Benhamou 2003). Muitos trabalhos ${ }^{3}$ consideram apenas os artistas como trabalhadores desse setor, e esses, por sua vez, ofertam trabalho diferentemente dos trabalhadores de outras indústrias, já que devido a diversos fatores, eles ofertam parte do tempo sua mão-de-obra como artistas e parte de seu tempo como trabalhadores tradicionais, a fim de poderem se sustentar e poder trabalhar também como artistas.

\footnotetext{
${ }^{1}$ Vale ressaltar que, ainda assim, essas características podem não ser suficientes para prover uma definição funcional de bens e serviços culturais (Throsby 2001).

${ }^{2}$ Outros trabalhos que podem ser destacados são: Cortes \& Monetti (2008), Diniz (2008), Diniz \& Machado (2009) , Ferreira Neto (2008), Machado et al. (2010) Santana \& Menezes (2008), Resende \& C. (2008), Valiati (2008), Diniz (2009) e Diniz \& Machado (2011)

${ }^{3}$ Seção 2.1 apresenta a revisão de literatura sobre o assunto.
} 
A identificação da natureza dos diferenciais salariais observados tem sido tema de interesse recorrente na literatura econômica. A busca por esta identificação é motivada por se constituir em importante ferramenta para formulação de políticas e mensuração do bem-estar individual. Os principais estudos realizados evidenciam o caráter estável e desigual dos diferenciais salariais, independentemente dos diversos arranjos institucionais e estruturais dos países (Gittleman \& Wollf 1993, Kahn 1998). Além disso, estas disparidades também persistem entre diferentes tipos de trabalhadores e tamanhos de estabelecimentos, mesmo após o controle por diferenças no capital humano, ocupação e outras variáveis observadas (Krueger \& Summers 1988, Teal 1996).

Grande parte desta literatura direciona suas análises aos diferenciais salariais inter-industriais (Krueger \& Summers (1987); Gibbons \& Katz (1992); Abowd et al. (1999); Bartel \& Shicherman (1999); Jackubson (1991). Poucos estudos, porém, se referem aos diferenciais de rendimentos na indústria da cultura, setor que recentemente vem ganhando projeção devido a sua crescente participação econômica. Dentre os estudos existentes, a maioria é voltada para a investigação dos salários interna ao setor cultural - também chamado de indústria da cultura ${ }^{4}$-, sem desenvolver, contudo, comparações detalhadas com os salários nos demais setores ${ }^{5}$.

Apesar de sua crescente importância, contudo, poucos são estudos para este setor em especial, dificultando o acesso a ferramentas de subsídio a formulação de políticas e mensuração do bem-estar individual. Considerando a marcante característica de desigualdade de rendimentos presente no país ${ }^{6}$, sua vasta extensão territorial e diversidades locais, uma questão imediata se apresenta: qual a magnitude e significância dos diferenciais salariais no setor cultural e em suas ocupações artísticas no Brasil?

É neste sentido que se estabelece o objetivo deste artigo, que busca analisar até que ponto trabalhadores engajados em atividades da indústria da cultura e ocupações artísticas podem ter rendimentos significativamente diferenciados em relação àqueles inseridos em outras atividades não pertencentes ao setor cultural. Especificamente, utilizando os microdados provenientes das PNAD's de 2002 a 2007, busca-se decompor o diferencial em fatores explicados e não explicados pelo modelo, identificando, portanto, se o setor cultural remunera de forma diferente seus trabalhadores por características observadas e não-observadas.

Para tanto, foi utilizado o estimador de efeitos fixos em um modelo de pseudo painel de coortes, considerando a correção viés de seleção por meio do procedimento de Heckman (1979), para se estimar os diferenciais salariais. A fim de capturar o efeito do setor cultural implementou-se a decomposição de Blinder (1973) e Oaxaca (1973) aperfeiçoada pelo método proposto por Jann (2008).

Tendo em vista a escassez de trabalhos, tanto na literatura nacional quanto internacional, que abordem a questão dos diferenciais salariais dos trabalhadores envolvidos neste importante setor econômico, o cultural, a principal contribuição deste artigo se constitui na investigação destes diferenciais. Vale ressaltar que a análise feita para o setor cultural no Brasil utilizando-se mi-

\footnotetext{
${ }^{4}$ Towse \& Khakee (1992), Throsby (2001), Towse (2003) e Benhamou (2007).

${ }^{5} \mathrm{O}$ único estudo encontrado com esta abordagem foi o de Wetzels (2008).

${ }^{6}$ Langoni (1973), Bacha \& Taylor (1978), Gatica et al. (1995), Mendonça \& R. (1995), Pia et al. (1996).
} 
crodados foi realizada apenas por Diniz $(2008,2009)$, incorporando apenas as regiões metropolitanas. O presente artigo amplia a análise para todos os estados do país. Os principais resultados mostram que uma parcela considerável dos diferenciais salariais entre regiões, indústrias e ocupações pode ser atribuída a efeitos individuais observados e não-observados.

Este artigo se divide em mais cinco partes além desta introdução. Na segunda seção faz-se uma breve revisão da literatura sobre diferenciais salariais e o mercado de trabalho na indústria da cultura. Na terceira, apresentam-se os dados utilizados e faz-se uma breve descrição sobre o setor cultural no Brasil. Na quarta seção, por sua vez, é apresentada a metodologia utilizada nesse artigo. Na quinta seção, analisam-se os principais resultados obtidos. Por fim, apresentam-se as considerações finais.

\section{Mercado de trabalho no setor cultural e diferenciais salariais}

$\mathrm{Na}$ análise da questão dos possíveis diferenciais de rendimentos entre trabalhadores pertencentes à indústria da cultura e aqueles fora desta indústria, pode ser encontrado um amplo referencial de teoria e estudos empíricos. Grande parte desta literatura direciona suas análises aos diferenciais salariais inter-industriais, sem qualquer referência ao setor cultural em particular. Outra parte da literatura se preocupa em investigar os salários na indústria da cultura, sem desenvolver, contudo, comparações detalhadas com os salários nos demais setores.

\subsection{Mercado de trabalho no setor cultural}

Benhamou (2003) afirma que as formas diferenciadas de emprego são mais presentes entre os trabalhadores do setor cultural que nos trabalhadores de forma geral. Benhamou (2007) analisa detalhadamente o mercado de trabalho do setor cultural, abordando a contratação, a carreira artística, salários e rendimentos. Da mesma forma, Wassal \& Alper (1992), Throsby (1992) e Towse \& Khakee (1992) afirmam que o mercado de trabalho do setor cultural é diferenciado já que, por muitas vezes, é realizado em tempo parcial, além de ser pouco influenciado pela escolaridade.

Filer (1986), por sua vez, afirma que os trabalhadores desse tipo de indústria não são diferentes dos demais. Assim, a teoria do capital humano desenvolvida por Mincer-Becker também pode ser a eles aplicada. Markusen \& King (2003) trabalham com o desenvolvimento regional associado à idéia do trabalho de artistas. Towse (2006) afirma que, como o talento é equivalente à habilidade inata das pessoas, não pode ser capturado por estes modelos, sendo que o trabalho de Throsby (1994) evidencia a partir de equações mincerianas as diferenças decorrentes do talento.

Benhamou (2007) verificou que, apesar de notadamente acompanhada de um aumento no custo de produção, a contratação temporária é a que mais cresce na Europa em detrimento da contratação permanente. Menger (1989), Caves (2000) e Throsby (2001) afirmam que isto se deve a dois fatores: a) à diferença entre o esforço exigido e o objetivo a alcançar quanto ao caráter temporário do sucesso, já que estão sujeitos ao modismo; b) às diversas rejeições que o mundo das artes vai alimentando ao longo do tempo.

Uma conclusão interessante apresentada por Adler (1985) é que a carreira artística e sua remuneração não dependem somente do talento e estudo, mas 
também da sorte e do acaso. A seleção do talento, portanto, não ocorre somente devido às forças do mercado, mas também devido a outras formas, estando relacionada com o processo de mimetização das escolhas dos indivíduos. Friedman \& Savage (1952) propuseram um modelo teórico que pode explicar o porque de artistas escolherem de maneira racional uma carreira tão incerta. A conclusão chegada é que a utilidade marginal da sua renda cresce proporcionalmente às atividades de alto risco desempenhadas.

Em relação aos salários e rendimentos, Benhamou (2007) expõe o "modelo de alocação do tempo" de Throsby (1994). Neste modelo, é explicado como o artista que não pode se dedicar exclusivamente à arte aloca seu tempo entre o trabalho artístico e não-artístico de acordo com sua remuneração. Notase ainda que os artistas dependem também do rendimento de seus cônjuges. Pode-se afirmar, portanto, que o artista prefere dedicar mais a essa atividade se o salário da outra atividade for maior. Destaca-se que, além do salário direto e da remuneração do cônjuge, a remuneração do artista também é composta pelos direitos autorais, que de maneira indireta o remunera por sua obra durante certo período, assim como as patentes. Cabe ressaltar, entretanto, que este tópico é muito debatido por ser controverso.

Em linhas gerais, os trabalhos empíricos internacionais na área da economia da cultura lidam principalmente com o setor artístico. Wassal \& Alper (2006) fazem uma extensa revisão da literatura abordando o tema e identificando as principais estratégias para estimar os rendimentos de artistas. Seguindo o proposto por Wetzels (2008), o presente artigo busca avaliar a indústria cultural de forma global, ampliando-se, portanto, o mercado de trabalho para o setor cultural como um todo, ao invés de incluir apenas artistas. Devido à importância dos artistas no mercado cultural, as mesmas análises serão feitas considerando apenas esse grupo, o que permitirá também a comparação entre ambos, indústria cultural como um todo e artistas somente.

\subsection{Diferenciais de salários}

Um dos temas mais investigados na literatura de economia do trabalho se refere aos diferenciais salariais. Nesta perspectiva destacam-se duas linhas investigativas acerca dos diferenciais salariais. A primeira destaca que a existência dos diferenciais ocorre graças à competitividade entre empresas dos diversos setores industriais na busca pelos trabalhadores, corroborando, portanto, a visão de que esses diferenciais ocorreriam de forma transitória, enquanto essas indústrias não se ajustassem ao equilíbrio de mercado, ou seja, esses diferenciais poderiam ser vistos como decorrentes das diferentes estruturas industriais de cada região. A outra abordagem reflete a heterogeneidade entre os trabalhadores, destacando, para tanto, que as diferenças observáveis entre os trabalhadores são consideradas determinantes pelos empregadores na definição de seus salários, já que, devido ao desconhecimento acerca das reais habilidades dos trabalhadores, os empregadores buscam minimizá-lo considerando seu nível educacional e sua experiência no mercado de trabalho e no setor.

Krueger \& Summers (1987) analisam os salários inter-industriais em sua estrutura e concluem que o modelo competitivo não explica adequadamente a estrutura salarial inter-industrial sem uma substancial modificação. Segundo Krueger \& Summers (1988) , a existência de diferenciais salariais caracteriza- 
se pela persistência ao longo dos anos, ou seja, pela pequena tendência de convergência salarial.

Gittleman \& Wollf (1993) e Kahn (1998), analisando diversos países com suas respectivas estruturas industriais, corroboram o caráter constante dos salários e trazem evidências adicionais acerca da desigualdade de rendimentos. Destacam-se como razões para essa desigualdade: a) assimetria de informação - há um custo de monitoramento, que pode ser alto ou difícil; b) alto custo de reposição - há um custo de treinamento além de que haverá informações que poderão se perder na transição; c) modelo de seleção adversa - um salário alto estimula trabalhadores bem qualificados; d) modelo sociológico - o salário alto estimula o moral do trabalhador (Fields \& Wolff 1995).

Dickens \& Katz (1987) concluem que o modelo de equilíbrio do mercado de trabalho padrão pode não explicar facilmente todos os fatos, sendo que os modelos de salário eficiência e modelos de risco de ação coletiva são mais consistentes com os fatos, ainda que alguns problemas permaneçam. Esses problemas decorrem, por exemplo, quando se observam firmas que pagam salários diferenciados a trabalhadores que apresentam as mesmas características observáveis. Este fato é um indicativo de que os diferenciais podem possuir mais um fator explicativo, a saber, as heterogeneidades não-observáveis, ou seja, indivíduos mais habilidosos obteriam maiores salários do que os menos habilidosos (Jackubson 1991).

Keane (1993), a partir de estimadores de efeitos fixos, mostra que os salários são acíclicos, o que vai contra a teoria de salários eficiência, já que essa teoria aponta para salários relativamente rígidos. Shippen (1999) corrobora o trabalho de Keane (1993) evidenciando que as habilidades não-observadas podem ser um fator significante no diferencial de salários inter-industriais de maneira geral. Resultados semelhantes são encontrados nos seguintes trabalhos: Groshen (1991), Jackubson (1991), Abowd et al. (1999), Carruth (2004), Murphy \& Topel (1987).

Blackburn \& Neumark (1992) concluem, porém, que as diferenças nas habilidades não observadas explicam relativamente pouco do diferencial de salários inter-industriais ou inter-ocupacionais. Outros trabalhos não encontram evidências de que a consideração dessas características não-observáveis seria significativa para explicar o comportamento salarial, tais como Krueger \& Summers (1988) e Gibbons \& Katz (1992).

Gibbons \& Katz (1992), analisando essa literatura sobre os diferenciais afirmam que, talvez, nenhuma teoria possa explicar completamente esses diferenciais salariais considerando todos os elementos que os explicativos para tal. Vale salientar, dessa forma, que os mercados de trabalhos para o setor cultural tendem a funcionar da mesma forma que para outros setores. Logo, as teorias a eles aplicadas podem ser aplicadas também no caso do setor cultural, sem prejuízos (Filer 1986).

\section{Análise descritiva dos dados}

\subsection{A importância do setor cultural no Brasil}

Diniz (2008) destaca a importância do setor cultural não só no Brasil como no mundo. A autora destaca, além da geração de empregos e da produção, os efeitos multiplicadores. A partir de dados da Unesco, ela constata a menor participação do setor cultural no PIB Argentino e em alguns países europeus, 
$5 \%$ e $3 \%$ respectivamente (comparados a quase $11 \%$ no Brasil). Além disso, destaca também o setor audiovisual americano, sendo o segundo mais importante nos EUA.

A tabela 1 resume os principais dados do setor cultural no país. Quando analisado o número de empresas, percebe-se um crescimento que não é exclusivo do setor cultural. Porém, dada a participação do setor cultural no total da indústria brasileira, é notável o crescimento do primeiro nos últimos anos a taxas maiores que as da indústria em geral. O número de pessoas empregadas também vem crescendo, assim como nos demais setores. O emprego no setor cultural representa aproximadamente $5 \%$ das pessoas empregadas no país, além de possuir um salário médio cerca de $160 \%$ comparativamente à indústria como um todo.

Tabela 1: Dados do setor cultural e da indústria total no Brasil

\begin{tabular}{|c|c|c|c|c|c|c|c|c|c|}
\hline \multirow{2}{*}{ Ano } & \multicolumn{3}{|c|}{ Número de empresas } & \multicolumn{3}{|c|}{ Pessoal Ocupado } & \multicolumn{3}{|c|}{ Salário Médio } \\
\hline & Total & Cultural & $\%$ & Total & Cultural & $\%$ & Total & Cultural & $\%$ \\
\hline 2003 & 2.298 .312 & 128.674 & 5,6 & 18.196 .858 & 984.849 & 5,41 & 3,3 & 5,4 & 163,64 \\
\hline 2004 & 2.358 .242 & 136.028 & 5,77 & 19.663 .877 & 1.059 .345 & 5,39 & 3,2 & 5,3 & 165,63 \\
\hline 2005 & 2.526 .625 & 153.669 & 6,08 & 20.960 .033 & 1.117 .906 & 5,33 & 3,0 & 5,0 & 166,67 \\
\hline \multirow{2}{*}{ Ano } & \multicolumn{3}{|c|}{ Valor Bruto da Produção† } & \multicolumn{3}{|c|}{ Gasto orçamentárioł } & & & \\
\hline & Total & Cultural & $\%$ & Total & Cultural & $\%$ & & & \\
\hline 2003 & 1.375 .775 .404 & 150.521 .203 & 10,94 & 1.208 .814 .474 & 2.358 .084 & 0,2 & & & \\
\hline 2004 & 1.650 .616 .502 & 179.516 .479 & 10,88 & 1.282 .899 .039 & 2.581 .670 & 0,2 & & & \\
\hline 2005 & 1.809 .695 .178 & 199.746 .956 & 11,04 & 1.538 .810 .372 & 3.129 .414 & 0,2 & & & \\
\hline
\end{tabular}

Quanto à produção no setor cultural, também é possível perceber que esta não só vem crescendo, como a cada ano se torna mais importante. Em 2005, sua participação na produção brasileira superava $11 \%$. Apesar desses números e das diversas leis de apoio à cultura, o governo investe apenas $0,2 \%$ de seus recursos na área cultural.

Em 1998, segundo o relatório do Ministério da Cultura realizado pela Fundação João Pinheiro, os trabalhadores do setor cultural eram 30\% mais bem remunerados que os trabalhadores do setor não-cultural. Como destaca Bertini (2008), o setor cultural, além de remunerar melhor, ainda gerou mais empregos em geral que o restante da economia. Esses dados são corroborados pelos dados do Sistema de Informação e Indicadores Culturais 2003-2005 apresentados na tabela 1 .

Já em 2007, o Ministério da Cultura em outra parceria, desta vez com o IPEA, gerou novo relatório com dados posteriores aos analisados pela Fundação João Pinheiro. Com resultados para a remuneração muito semelhantes aos do primeiro relatório, foi constatado que o Setor Cultural remunera aproximadamente $30 \%$ a mais os seus trabalhadores em relação aos demais setores.

\subsection{Análise dos dados}

Para se estimar o diferencial de salários entre setor cultural e não cultural, foi realizado um pooling com dados da Pesquisa Nacional por Amostra de Domićllios (PNAD) de 2002 a 2007. A PNAD é realizada anualmente pelo Instituto Brasileiro de Geografia e Estatística (IBGE), por exceção dos anos de censo, 
e traz informações tanto de setores formais quanto informais da economia. É importante ressaltar que os anos anteriores não foram utilizados devido à falta de compatibilidade entre as variáveis de classificação de ocupação e atividades, visto que a partir de 2002 a PNAD passou a utilizar a classificação CNAE - Classificação Nacional de Atividades Econômicas - e CBO - Classificação Brasileira de Ocupações. Assim, foi possível evitar um enviesamento dos resultados devido essa incompatibilidades dos códigos.

Wetzels (2008) sugere que sejam comparados ao grupo e à seção da CNAE 1.0 no Brasil. Porém por questões metodológicas referente à base de dados, optou-se pela definição de um setor cultural e outro não-cultural formado pelo restante dos setores, com exceção da agricultura, que não integrou o banco de dados.

O setor cultural neste trabalho seguiu indicações do Sistema de Informações e Indicadores 2003-2005, definindo o setor cultural a partir dos códigos CNAE presentes na PNAD (Anexo A.1) cruzando com informações referentes à ocupação de cada indivíduo, de acordo com a CBO (Anexo A.2). Essa abordagem vai ao encontro da definição de cunho funcional de Throsby (2001), que se justifica diante do objetivo do presente estudo. Desta forma foi possível restringir de forma consistente aqueles trabalhadores engajados em atividades culturais propriamente ditas. A partir dos códigos da CBO e CNAE foi possível também restringir àqueles indivíduos que podem ser considerados $\operatorname{artistas}^{7}$. O Anexo A. 3 apresenta as estatísticas descritivas dos indivíduos presentes no banco de dados ${ }^{8}$.

\section{Metodologia}

Para identificar os diferenciais salariais e se há algum tipo de discriminação em relação ao setor cultural, ou até mesmo do próprio setor, o procedimento metodológico adotado consiste em duas etapas. Primeiro, estima-se o diferencial de rendimento entre trabalhadores da indústria da cultura vis-à-vis os demais trabalhadores pertencentes a outros setores. A forma funcional destas regressões está baseada na equação minceriana (Mincer 1974), expandida por um conjunto de outras variáveis explicativas, como pode ser observado na equação (1).

$$
\ln w_{i t}=X_{i t} \beta+I_{i t} \delta+\mu_{t}+v_{i}+\varepsilon_{i t}
$$

onde $\ln w_{i t}$ é o logaritmo natural do real salário do trabalhador i; $X_{i t}$ é um vetor de variáveis de controle, incluindo idade, idade ao quadrado, experiência, experiência ao quadrado, educação,dummy de gênero, setor informal, dummies de raça/cor, dummies de estados e de ano; $I_{i t}$ é a dummy de interesse que identifica o setor cultural $\left(I_{i t}=1\right)$ e o setor não-cultural $\left(I_{i t}=0\right) ; \beta$ e $\delta$ são vetores de parâmetros a serem estimados, $\mu_{t}$ é termo de efeito específico temporal, $v_{i}$ é o termo de efeito fixo individual, e $\varepsilon_{i t}$ é o termo de erro aleatório.

Tendo em vista a possibilidade de existência de viés decorrente de variáveis omitidas que tornariam endógenas as estimações dos diferenciais salariais no setor cultural, pode-se utilizar o método de pseudo-painéis (Baltagi 2005).

\footnotetext{
${ }^{7}$ A marcação dos códigos utilizados para artistas estão marcados nos Anexos A.1 e A.2.

${ }^{8}$ Em todo o artigo, as análises incorporaram a expansão amostral pelos pesos das PNAD's utilizadas.
} 
De maneira simples, uma das formas de se estimar vi é adicionar uma variável dummy para cada indivíduo. Assim, insere-se uma variável dummy para cada coorte como forma de capturar os efeitos fixos das gerações. A hipótese de identificação do modelo, portanto, é a de que as habilidades inatas dos indivíduos, capturadas pelas coortes, são fixas em cada geração e não são correlacionadas com as variáveis de interesse Xit e Iit. O talento individual, importante no setor cultural, passa a ser controlado.

É importante ressaltar que, mesmo com o controle de efeitos fixos de gerações, há a possibilidade de existência de seleção amostral. A forma usual da literatura para solucionar problemas de endogeneidade deste tipo envolve a utilização do método de Heckman (1979). O viés de seleção pode ocorrer quando se exclui os desempregados e inativos da regressão minceriana de salários, que não possuem empregos remunerados. O fato é que, ao excluí-los da amostra, o processo de seleção pode não ser aleatório, isto é, pode não ser representativo de toda a população. Isto pode levar a estimativas inconsistentes e enviesadas. A equação de seleção, portanto, é definida pelo probit da variável de participação no mercado de trabalho dos indivíduos, independentemente de serem ocupados, desempregados ou inativos. Como variáveis de controle, foram utilizadas condição de chefe no domicílio, condição de cônjuge no domicílio, condição de filho na família, e haver criança de 0 a 5 anos no domicílio. A equação (2) representa o modelo probit a ser estimado.

$$
\operatorname{Pr}_{i}=c_{i}+Z_{i} \gamma_{i}+e_{i}
$$

onde $P r_{i}$ é a variável binária dependente do probit, que assume um valor " 0 " caso a pessoa não tenha ocupação profissional e não tenha renda, e assume valor " 1 " caso o contrário. $c_{i}$ é o intercepto, $\gamma_{i}$ são os parâmetros a serem estimados, $Z_{i}$ são as variáveis explicativas, já definidas, do modelo e eié o termo de erro aleatório.

A partir do modelo probit, calcula-se a Razão de Mills Invertida (RMI) e esta é acrescida como variável explicativa da equação (1) e posteriormente na decomposição de Oaxaca, de modo a capturar o viés de seleção do modelo. A equação (3) evidencia o modelo a ser estimado já com a RMI $\left(\lambda_{i}\right)$ inserida.

$$
\ln w_{i t}=X_{i t} \beta+I_{i t} \delta+\mu_{t}+v_{i}+\lambda_{i}+\varepsilon_{i t}
$$

onde $\ln w_{i t}$ é o logaritmo natural do real salário do trabalhador $\mathrm{i} ; X_{i}$ é um vetor de variáveis de controle, definidas na equação (1), $\beta$ é o vetor de parâmetros a serem estimados, $\lambda_{i}$ é Razão Inversa de Mills e $\varepsilon_{i}$ é o termo de erro aleatório.

Na segunda etapa, para detectar se o setor cultural tem a mesma remuneração do setor não-cultural, será realizada a decomposição de Oaxaca (1973), também conhecida como Oaxaca-Blinder.A decomposição de Oaxaca é utilizada para mensurar os efeitos da discriminação ou de políticas públicas. Como destaca Borjas (1996), o salário é a variável sensível a esta discriminação, podendo ser decomposto em duas partes. A primeira é a parte explicada em função das diferenças dos grupos enquanto que a segunda constitui-se na parte não explicada.

Em um primeiro momento são estimadas regressões para cada grupo, setor cultural e não-cultural (equação 4).

$$
\ln w_{i j}=\alpha_{i j}+\sum X_{i j} \beta_{i j}+\varepsilon_{i j}
$$


onde $\ln w_{i j}$ é o logaritmo natural do real salário do trabalhador i; $X_{i j}$ são as variáveis de características do trabalhador $\mathrm{i} ; \beta_{i j}$ são os parâmetros a serem estimados; $\varepsilon_{i j}$ é o termo de erro aleatório; o subscrito $j=1,2$ representa respectivamente os setores cultural e não cultural.

A análise é realizada no ponto médio das variáveis e parâmetros. Subtraindo então $j=1$ de $j=2$, obtém-se a equação (5).

$$
\ln w_{i 1}-\ln w_{i 2}=\alpha_{i 1}-\alpha_{i 2}+\sum X_{i 1} \beta_{i 1}+\sum X_{i 2} \beta_{i 2}
$$

Somando e subtraindo o termo (Fórmula 6) e fazendo algumas manipulações algébricas, obtém-se a equação (6).

$$
\ln w_{i 1}-\ln w_{i 2}=\left(\alpha_{i 1}-\alpha_{i 2}\right)+\sum \beta_{i 1}\left(X_{i 1}-X_{i 2}\right)-\sum X_{i 2}\left(\beta_{i 1}-\beta_{i 2}\right)
$$

O termo é a diferença entre interceptos e indica, independente do nível das variáveis, quão melhor remunerado é um grupo em relação ao outro. $\mathrm{O}$ segundo termo, indica as diferenças na remuneração devido às características de cada grupo. Caso não houvesse discriminação no mercado, ele remuneraria ambos os grupos como está descrito neste componente. Finalmente, o terceiro termo, é a valorização diferente de um mesmo atributo. Este último foi o componente que Oaxaca (1973) chamou de termo de discriminação.

Em linhas gerais, a decomposição de Oaxaca-Blinder pode ser dividida em duas partes: (a) características produtivas dos indivíduos de cada grupo (E); e (b) diferentes critérios de remuneração de cada setor (D). No presente artigo, como se está analisando a diferença entre setor cultural e não-cultural, essa é a melhor forma a ser seguida na interpretação dos dados. Reescrevendo (6):

$$
\ln w_{i 1}-\ln w_{i 2}=D+E
$$

onde $D=\left(\alpha_{i 1}-\alpha_{i 2}\right)+\sum X_{i 2}\left(\beta_{i 1}-\beta_{i 2}\right)$ e $E=\sum \beta_{i 1}\left(X_{i 1}-X_{i 2}\right)$.

Uma terceira parcela de decomposição, que seria a interação entre ambas, ou seja, $\mathrm{D}^{\star} \mathrm{E}$, pode ser também relevante. Porém, dependendo do modelo assumido como não discriminatório, este termo pode ser usado tanto na parte não explicada (U) do modelo como na parte explicada (V). Oaxaca (1973) sugere que se assuma um dos grupos do modelo, lowgroup ou high group, como não discriminatório, daí segue-se: $U=D+D E$ e $V=E$ ou $U=D$ e $V=E+D E$, respectivamente.

Como a decomposição dos diferenciais é realizada a partir de médias de coeficientes e variáveis explicativas adicionadas ao modelo, estas podem ser não significativas. Assim a partir do teste das médias, a metodologia proposta por Jann (2008) é capaz de produzir estimadores não enviesados da variância de cada componente da decomposição, como destacado por Moriconi \& Marconi (2008).

\section{Discussão dos resultados}

Essa seção apresenta num primeiro momento as análises das regressões para o setor de cultura agregado e, num segundo momento, são apresentados resultados somente para aqueles considerados artistas. Em seguida são evidenciados os resultados da decomposição de Oaxaca propriamente ditos. Para todas as regressões utilizadas neste trabalho, a renda foi deflacionada pelo deflator da 
PNAD proposto pelo IPEA (2011). Dummies de controle por estados e de efeitos fixos de ano e coorte foram incluídas para determinadas regressões. As regressões foram implementadas no software Stata 11 aplicando a correção de White. As dummies de brancos, do estado de São Paulo, da coorte 1 e do ano de 2002 foram selecionadas como categorias omitidas.

As Tabela 2 e 3 apresentam quatro modelos das estimativas dos diferenciais salariais. Os modelos (1) na Tabela 2 e (5) na Tabela 3 se referem ao modelo de mínimos quadrados ordinários (MQO) tradicional. Os modelos (2) e (6) se referem aos diferenciais salariais internos ao setor cultural e à classe artística, ou seja, para o caso da dummy de interesse ser igual a 1. Os modelos (3) e (7), referentes às Tabela 2 e Tabela 3 , respectivamente, acrescentam a correção do viés de seleção nas estimativas. Por fim, os modelos (4) e (8) apresentam as estimativas para o pseudo painel de coortes. Um maior detalhamento de cada modelo pode ser observado nas notas explicativas das Tabela 2 e Tabela 3.

A Tabela 2, então, apresenta as estimativas dos diferenciais salariais analisando o caso do setor cultural. Como pode ser visto, os modelos corroboram estudos prévios em que os trabalhadores do setor cultural são melhores remunerados que os do setor não-cultural, sendo esta diferença de $26 \%$ a mais. Olhando as demais variáveis, nota-se que como esperado, que experiência, anos de estudo, idade e ser mulher, remuneram positivamente em torno de $3 \%, 10 \%, 6 \%$ e mais que $20 \%$ respectivamente. Porém, dado que o interesse deste trabalho reside nos setores ou grupos de cultura e artistas, a análise do modelo (2) se torna interessante, comparando-o principalmente com o modelo (1).

O modelo (2) é uma análise intra-setorial, ou seja, como ela estima a equação de rendimentos apenas considerando os indivíduos do setor cultural.

Neste caso nota-se que a experiência e a idade são melhores remuneradas para esses trabalhadores, enquanto o estudo e ser do sexo feminino são menos remunerados, tal que o último merece maior destaque visto a grande diferença ( $8 \%$ versus acima de $20 \%$ ). Esses resultados são sustentados mesmo controlando pelo viés de seleção e efeitos fixos.

Observando os modelos (3) e (4) é possível notar que o viés de seleção tem um efeito negativo nas estimativas dos diferenciais salariais, ou seja, ele sem o mesmo, as estimativas estão superestimadas. No modelo (4) em que há o controle de efeitos fixos temporais e de coortes, nota-se que esses subestimam a importância do efeito de seleção e apresentam a mesma característica do lambda, ou seja, sem os mesmo, as estimativas estão superestimadas.

A Tabela 3, por sua vez, apresenta as estimativas para o caso dos artistas. Neste caso, essas estimativas apontam para uma remuneração maior dos artistas em torno de 56\%. Esse resultado é interessante, visto que não há consenso na literatura e nem em trabalhos empíricos acerca dos diferenciais de remuneração dos artistas.

Seguindo a mesma sequencia analítica da Tabela 2 para a Tabela 3, notase com controles para artistas e setor cultural as estimativas para as demais variáveis são similares, tal que experiência, estudos, idade e ser do sexo feminino remuneram positivamente os trabalhadores na mesma magnitude para o controle de setor cultural. Entretanto, ao se analisar o modelo (6) que mostra a estimativa dos rendimentos apenas para os artistas, nota-se que experiência e estudo como no caso do setor cultural remuneram melhor e pior, respectivamente, que no caso dos demais modelos. Porém idade também remunera pior ao contrário do caso do setor cultural, e ser do sexo feminino mantém a 
Tabela 2: Regressões dos modelos propostos para o setor cultural

\begin{tabular}{|c|c|c|c|c|}
\hline Variáveis & $\begin{array}{l}\text { (1) } \\
\text { Lw }\end{array}$ & $\begin{array}{l}(2) \\
\text { Lw }\end{array}$ & $\begin{array}{l}\text { (3) } \\
\text { Lw }\end{array}$ & $\begin{array}{l}(4) \\
\mathrm{Lw}\end{array}$ \\
\hline Dcult & $\begin{array}{l}0,260^{* * *} \\
(0,0255)\end{array}$ & & $\begin{array}{l}0,261^{* * *} \\
(0,0255)\end{array}$ & $\begin{array}{l}0,259^{* * *} \\
(0,0255)\end{array}$ \\
\hline Exp & $\begin{array}{l}0,0296^{* * *} \\
(0,000289)\end{array}$ & $\begin{array}{l}0,0354^{* * *} \\
(0,00508)\end{array}$ & $\begin{array}{l}0,0295^{* * *} \\
(0,000289)\end{array}$ & $\begin{array}{l}0,0300^{* * *} \\
(0,000288)\end{array}$ \\
\hline Exp2 & $\begin{array}{c}-0,000638^{* * *} \\
(9,63 e-06)\end{array}$ & $\begin{array}{c}-0,000762^{* * *} \\
(0,000177)\end{array}$ & $\begin{array}{c}-0,000638^{* * *} \\
(9,63 e-06)\end{array}$ & $\begin{array}{c}-0,000653^{* * *} \\
(9,61 e-06)\end{array}$ \\
\hline Estudo & $\begin{array}{l}0,105^{* * *} \\
(0,000221)\end{array}$ & $\begin{array}{l}0,0818^{* * *} \\
(0,00422)\end{array}$ & $\begin{array}{l}0,105^{* * *} \\
(0,000221)\end{array}$ & $\begin{array}{l}0,104^{* * *} \\
(0,000222)\end{array}$ \\
\hline Idade & $\begin{array}{l}0,0620^{* * *} \\
(0,000438)\end{array}$ & $\begin{array}{l}0,0701^{* * *} \\
(0,00822)\end{array}$ & $\begin{array}{l}0,0609^{* * *} \\
(0,000439)\end{array}$ & $\begin{array}{l}0,0619^{* * *} \\
(0,00107)\end{array}$ \\
\hline Idade2 & $\begin{array}{c}-0,000591^{* * *} \\
(5,83 e-06)\end{array}$ & $\begin{array}{c}-0,000748^{* * *} \\
(0,000113)\end{array}$ & $\begin{array}{c}-0,000582^{* * *} \\
(5,84 e-06)\end{array}$ & $\begin{array}{c}-0,000621^{* * *} \\
(1,54 e-05)\end{array}$ \\
\hline Dfem & $\begin{array}{l}0,238^{* * *} \\
(0,00170)\end{array}$ & $\begin{array}{l}0,0886^{* * *} \\
(0,0306)\end{array}$ & $\begin{array}{l}0,219^{* * *} \\
(0,00173)\end{array}$ & $\begin{array}{c}0,208^{* * *} \\
(0,00190)\end{array}$ \\
\hline Lambda & & & $\begin{array}{c}-0,170^{* * *} \\
(0,00386)\end{array}$ & $\begin{array}{c}-0,278^{* * *} \\
(0,00839)\end{array}$ \\
\hline Uf & Sim & Sim & Sim & Sim \\
\hline Cor & Sim & Sim & Sim & Sim \\
\hline Ocupação & Sim & Sim & Sim & Sim \\
\hline Ocupação * Dcult & Sim & Sim & Sim & Sim \\
\hline Ano & Não & Não & Não & Sim \\
\hline Coorte & Não & Não & Não & Sim \\
\hline Constante & $-{ }^{-1,192^{* * *}}$ & $\begin{array}{c}-0,680^{* * *} \\
(0,149)\end{array}$ & $-1,128^{* * *}$ & $\begin{array}{c}-1,129^{* * *} \\
(0,0160)\end{array}$ \\
\hline Observações & 937.721 & 5.349 & 1.027 .218 & 937.721 \\
\hline R-quadrado & 0,46 & 0,28 & & 0,465 \\
\hline \multicolumn{5}{|c|}{$\begin{array}{l}\text { Nota: (i) Erros padrões robustos em parênteses }{ }^{* *} \mathrm{p}<0,01 \text {, }^{* *} \mathrm{p}<0,05,{ }^{*} \mathrm{p}<0,1 \text {. (ii) } \mathrm{O} \\
\text { modelo (1) é o modelo de MQO proposto com a inclusão da dummy de setor } \\
\text { cultural. O modelo (2) é o modelo (1) estimado para dcult }=1 \text {. O modelo (3) é o } \\
\text { modelo } 1 \text { estimado com a inclusão de lambda. O modelo (4) é o modelo de } \\
\text { pseudo-painel com correção de viés de seleção - inclusão de dummies de coorte, } \\
\text { e ano e a variável lambda no modelo (1). (iii) A fórmula funcional do modelo (1) } \\
\text { é: } \\
\text { Fonte: }\end{array}$} \\
\hline
\end{tabular}

mesma remuneração que no caso do modelo (5) e próximo aos dos modelos (7) e (8).

Os modelos (7) e (8) apresentam efeito semelhante aos modelos (3) e (4), ou seja, o viés de seleção possui um efeito negativo nas estimativas dos diferenciais salariais superestimando-as, e o controle de efeitos fixos temporais e de coortes também subestimam a importância do efeito de seleção e apresentam superestimam as estimativas. Cabe destacar que a Tabela 4 evidencia o modelo Probit para o cálculo da Razão de Mills Inversa.

Como explicitado na teoria e na seção metodológica, a existência dos diferenciais salariais podem ocorrer por diversas razões, sendo que a metodologia de decomposição de Oaxaca permite que sejam comparados dois grupos, ou seja, ela fornece evidências de quanto um grupo é remunerado diferente apenas pelo fato de pertencer a este determinado grupo. Assim a Tabela 5 apresenta a decomposição de Oaxaca considerando o grupo de setor cultural (modelos 12 e 13) e de artistas (modelos 14 e 15), sendo que no primeiro modelo para cada grupo não há controle de efeito fixo e nem de viés de seleção, enquanto no segundo esses controles são incluídos.

Comparativamente, é possível notar que a diferença bruta (magnitude do 
Tabela 3: Regressões dos modelos propostos para os artistas

\begin{tabular}{|c|c|c|c|c|}
\hline Variáveis & $\begin{array}{l}\text { (5) } \\
\text { Lw }\end{array}$ & $\begin{array}{l}\text { (6) } \\
\text { Lw }\end{array}$ & $\begin{array}{l}\text { (7) } \\
\text { Lw }\end{array}$ & $\begin{array}{l}\text { (8) } \\
\text { Lw }\end{array}$ \\
\hline Dart & $\begin{array}{l}0,562^{* * *} \\
(0,0481)\end{array}$ & & $\begin{array}{l}0,562^{* * *} \\
(0,0485)\end{array}$ & $\begin{array}{l}0,558^{* * *} \\
(0,0485)\end{array}$ \\
\hline Exp & $\begin{array}{l}0,0295^{* * *} \\
(0,000289)\end{array}$ & $\begin{array}{l}0,0376^{* * *} \\
(0,00958)\end{array}$ & $\begin{array}{l}0,0295^{* * *} \\
(0,000289)\end{array}$ & $\begin{array}{l}0,0299^{* * *} \\
(0,000288)\end{array}$ \\
\hline Exp2 & $\begin{array}{c}-0,000638^{* * *} \\
(9,63 e-06)\end{array}$ & $\begin{array}{c}-0,000892^{* * *} \\
(0,000289)\end{array}$ & $\begin{array}{c}-0,000638^{* * *} \\
(9,63 e-06)\end{array}$ & $\begin{array}{c}-0,000653^{* * *} \\
(9,61 e-06)\end{array}$ \\
\hline Estudo & $\begin{array}{c}0,105^{* * *} \\
(0,000221)\end{array}$ & $\begin{array}{l}0,0596^{* * *} \\
(0,00880)\end{array}$ & $\begin{array}{l}0,105^{* * *} \\
(0,000221)\end{array}$ & $\begin{array}{l}0,104^{* * *} \\
(0,000222)\end{array}$ \\
\hline Idade & $\begin{array}{l}0,0620^{* * *} \\
(0,000438)\end{array}$ & $\begin{array}{l}0,0558^{* * *} \\
(0,0154)\end{array}$ & $\begin{array}{l}0,0610^{* * *} \\
(0,000439)\end{array}$ & $\begin{array}{l}0,0619^{* * *} \\
(0,00107)\end{array}$ \\
\hline Idade2 & $\begin{array}{c}-0,000591^{* * *} \\
(5,83 e-06)\end{array}$ & $\begin{array}{c}-0,000631^{* * *} \\
(0,000204)\end{array}$ & $\begin{array}{c}-0,000583^{* * *} \\
(5,84 e-06)\end{array}$ & $\begin{array}{c}-0,000622^{* * *} \\
(1,54 e-05)\end{array}$ \\
\hline Dfem & $\begin{array}{l}0,239^{* * *} \\
(0,00170)\end{array}$ & $\begin{array}{l}0,235^{* * *} \\
(0,0652)\end{array}$ & $\begin{array}{c}0,220^{* * *} \\
(0,00173)\end{array}$ & $\begin{array}{l}0,208^{* * *} \\
(0,00190)\end{array}$ \\
\hline Lambda & & & $\begin{array}{c}-0,170^{* * *} \\
(0,00386)\end{array}$ & $\begin{array}{c}-0,279^{* * *} \\
(0,00839)\end{array}$ \\
\hline Uf & Sim & Sim & Sim & Sim \\
\hline Cor & Sim & Sim & Sim & Sim \\
\hline Ocupação & Sim & Sim & Sim & Sim \\
\hline Ocupação * Dcult & Sim & Sim & Sim & Sim \\
\hline Ano & Não & Não & Não & Sim \\
\hline Coorte & Não & Não & Não & Sim \\
\hline Constante & $\begin{array}{c}-1,193^{* * *} \\
(0,00819)\end{array}$ & $\begin{array}{c}-0,00699 \\
(0,293)\end{array}$ & $\begin{array}{c}-1,129^{* * *} \\
(0,00830)\end{array}$ & $\begin{array}{c}-1,130^{* * *} \\
(0,0160)\end{array}$ \\
\hline Observações & 937.721 & 1.802 & 1.027 .218 & 937.721 \\
\hline R-quadrado & 0,46 & 0,174 & & 0,465 \\
\hline \multicolumn{5}{|c|}{$\begin{array}{l}\text { Nota: (i) Erros padrões robustos em parêntesis }{ }^{* * *} \mathrm{p}<0,01,{ }^{* *} \mathrm{p}<0,05,{ }^{*} \mathrm{p}<0,1 \text {. (ii) } \mathrm{O} \\
\text { modelo (5) é o modelo de MQO proposto com a inclusão da dummy de artistas. } \\
\text { O modelo (6) é o modelo (5) estimado para dart }=1 \text {. O modelo }(7) \text { é o modelo (5) } \\
\text { estimado com a inclusão de lambda. O modelo (8) é o modelo de pseudo-painel } \\
\text { com correção de viés de seleção - inclusão de dummies de coorte, e ano e a } \\
\text { variável lambda no modelo (5). (iii) A fórmula funcional do modelo (1) é: } \\
\text { Fonte: Resultado da pesquisa }\end{array}$} \\
\hline
\end{tabular}

Tabela 4: Modelo Probit para cálculo da Razão de Mills Inversa

\begin{tabular}{|c|c|c|c|}
\hline Variáveis & $\begin{array}{l}(9) \\
\operatorname{Pr}\end{array}$ & $\begin{array}{c}(10) \\
\text { Athrho }\end{array}$ & $\begin{array}{c}(11) \\
\text { Lnsigma }\end{array}$ \\
\hline Chefe & $\begin{array}{c}0,517^{* * *} \\
(-0,00831)\end{array}$ & & \\
\hline Conj & $-0,571^{* * *}$ & & \\
\hline Filho & $-{ }_{(-0,00777)}^{0,344^{* * *}}$ & & \\
\hline Constante & $\begin{array}{c}1,458^{* * *} \\
(-0,00701)\end{array}$ & $-{ }_{(-0,00579)}^{0,248^{* * *}}$ & $-{ }_{(-0,00126)}^{0,356^{* * *}}$ \\
\hline $\begin{array}{l}\text { Observações } \\
\text { R-quadrado }\end{array}$ & 1.027 .218 & 1.027 .218 & 1.027 .218 \\
\hline
\end{tabular}


diferencial) entre o setor cultural e não cultural é menor do que aquela apresentada entre os artistas e não artistas $(-0,577$ versus $-0,759)$. Porém, em ambos os casos a remuneração por pertencer ao grupo de interesse é maior comparativamente aos demais grupos ocupacionais.

Focando-se na comparação dos modelos para cada grupo é possível notar que para o caso do setor cultural, com a inclusão do controle de efeitos fixos e de viés de seleção, o termo de interação diminuiu de foram absoluta de -0,038 para 0,000. Neste sentido, o termo de características dos indivíduos passa de -2,229 para -0,269, sendo que o termo de discriminação (D) - conforme a definição dada por Oaxaca (1973) - evidencia ganhos em torno de 31\% para os trabalhadores do setor cultural em relação aos demais trabalhadores. Essa parcela é, portanto, maior que a parcela de características individuais (E), o que reforça a importância do referido setor na determinação dos diferenciais de salário.

Tabela 5: Decomposição de Oaxaca para o setor cultural e artistas

\begin{tabular}{|c|c|c|c|c|}
\hline Variáveis & $\begin{array}{l}(12) \\
\text { Lw }\end{array}$ & $\begin{array}{l}\text { (13) } \\
\text { Lw }\end{array}$ & $\begin{array}{l}(14) \\
\text { Lw }\end{array}$ & $\begin{array}{l}\text { (15) } \\
\text { Lw }\end{array}$ \\
\hline \multicolumn{5}{|l|}{ Diferenciais } \\
\hline Predição para dcult $/$ dart $=0$ & $\begin{array}{l}1.186^{* * *} \\
(0.00109)\end{array}$ & $\begin{array}{l}1.186^{* * *} \\
(0.00109)\end{array}$ & $\begin{array}{l}1.188^{* * *} \\
(0.00108)\end{array}$ & $\begin{array}{l}1.188^{* * *} \\
(0.00108)\end{array}$ \\
\hline Predição para dcult/dart $=1$ & $\begin{array}{l}1.764^{* * *} \\
(0.0148)\end{array}$ & $(0.0148)^{1.764^{* * *}}$ & $\begin{array}{l}1.948^{* * *} \\
(0.0309)\end{array}$ & $\begin{array}{l}1.948^{* * *} \\
(0.0308)\end{array}$ \\
\hline Diferença bruta & $-0.577^{* * *}$ & $\begin{array}{c}-0.577^{* * *} \\
(0.0148)\end{array}$ & $\begin{array}{l}-0.759^{* * *} \\
(0.0309)\end{array}$ & $\begin{array}{l}-0.759^{* * *} \\
(0.0308)\end{array}$ \\
\hline \multicolumn{5}{|l|}{ Decomposições } \\
\hline Características (E) & $-0.229^{* * *}$ & $-0.269^{* * *}$ & $-{ }^{0.170^{* * *}}$ & $-0.189^{* * *}$ \\
\hline Coeficientes (D) & $\begin{array}{r}-0.310^{* * *} \\
(0.0130)\end{array}$ & $\begin{array}{c}-0.309^{* * *} \\
(0.0130)\end{array}$ & $\begin{array}{c}-0.299^{* * *} \\
(0.0350)\end{array}$ & $\begin{array}{l}-0.303^{* * *} \\
(0.0349)\end{array}$ \\
\hline Interação $\left(D^{\star} E\right)$ & $-0.0385^{* * *}$ & $\begin{array}{l}7.62 e-07 \\
(0.0147)\end{array}$ & $-0.291^{* * *}$ & $-0.267^{* * *}$ \\
\hline Observations & 937,721 & 937,721 & 937,721 & 937,721 \\
\hline
\end{tabular}

No caso dos artistas, a inclusão dos controles de efeitos fixos e de viés de seleção diminui também o termo de interação, porém em menor proporção que no caso do setor cultural agregado, passando de $-0,291$ para $-0,267$. Como conseqüência, os outros dois termos, $\mathrm{D}$ e $\mathrm{E}$, passam de $-0,170$ para $-0,189$ e de $-0,299$ para $-0,303$, respectivamente. Portanto, há o aumento principalmente do termo de características individuais. Neste caso a remuneração pelo simples fato de ser artista é 30\% superior, sendo que essa componente se mostra maior do que a de características dos indivíduos.

\section{Considerações finais}

Este trabalho teve como objetivo a análise dos diferenciais salariais para o setor cultural e para os artistas no Brasil. Após considerar o processo de seleção no mercado de trabalho, incorporar características fixas relativas ao tempo e coortes, e decompor os rendimentos em efeitos observados e não-observados - que podem ser separados em de três fatores principais: i) características dos próprios trabalhadores; ii) características do setor; e iii) interação dos dois primeiros - importantes resultados foram obtidos. O setor cultural remunera 
mais seus trabalhadores e os artistas são melhores remunerados per se, e essa remuneração a mais é em torno de $31 \%$ e 30\%, respectivamente. Pode-se então afirmar que há uma discriminação positiva por parte do setor cultural. Outros resultados interessantes que, embora secundários, também merecem destaque são: i) mulheres também são remuneradas acima de $20 \%$ em relação aos homens; ii) idade remunera de forma diferente o setor cultural (mais) e os artistas (menos); iii) experiência se mostra mais importante para os grupos analisados e o estudo menos importante. Em linhas gerais, tais resultados reforçam a importância da indústria da cultura Brasil e podem direcionar políticas sociais específicas para a referida indústria como forma de redução das desigualdades salariais no país.

\section{Agradecimentos}

Os autores agradecem aos bolsistas do ECONS/UFJF e à coordenação do PPGEA/UFJF pelo fornecimento dos dados utilizados. Os autores agradecem também aos valiosos comentários dos pareceristas anônimos que contribuíram para o enriquecimento deste trabalho.

\section{Referências Bibliográficas}

Abowd, J. M., Kramarz, F. \& Margolis, D. N. (1999), 'High wage workers and high wage firms', Econometrica 67, 251-333.

Adler, M. (1985), 'Stardom and talent', The American Economic Review 75(1), 208-212.

Bacha, E. \& Taylor, L. (1978), 'Brazilian income distribution in the 60's: facts, model results and controversy', The Journal of Development Studies 14(3), 271-297.

Baltagi, B. H. (2005), Econometric analysis of panel data, 3rd edn, John Wiley AND Sons.

Bartel, A. P. \& Shicherman, N. (1999), 'Technological change and wages: An interindustry analysis', Journal of Political Economy 107(2).

Benhamou, F. (2003), Artists' labour market, in 'A Handbook of Cultural Economics', Edward-Elgar.

Benhamou, F. (2007), A economia da cultura, Cotia: Ateliê Editorial.

Bertini, A. (2008), Economia da cultura: a indústria do entretenimento e o audiovisual no Brasil, São Paulo: Saraiva.

Blackburn, M. \& Neumark, D. (1992), 'Unobserved ability, efficiency wages, and interindustry wage differentials', The Quarterly Journal of Economics 107(4), 1421-1436.

Blaug, M. (2001), 'Where are we on cultural economics?', Journal of Economic Surveys 15(2), 123-143.

Blinder, A. S. (1973), 'Wage discrimination: Reduced form and structural estimates.', The Journal of Human Resources 8(VII), 436-455. 
Borjas, G. J. (1996), Labor Economics, McGraw-Hill.

Carruth, A. e. a. (2004), 'Inter-industry wage differences and individual heterogeneity', Oxford Bulletin of Economics and Statistis 66(5).

Cassiolato, J. E. (2008), Indústria cultural versus indústria criativa: uma breve introdução para debate. nota técnica 01/2008 pesquisa "arranjos e sistemas produtivos e inovativos locais em Áreas intensivas em cultura e mobilizadoras de desenvolvimento social", Technical report, Rio de Janeiro/Fortaleza: REDESIST.

Caves, R. H. (2000), Creative Industries: Contracts Between Art and Commerce, Havard University Press.

Cortes, M. V. R. \& Monetti, E. (2008), Localização residencial e demanda por recreação: um modelo para cidades litorâneas, in 'Anais do VI ENABER Encontro Nacional da Associação Brasileira de Estudos Regionais. Aracaju'.

da Cultura, M. (2007), Economia e política cultural: acesso, emprego e financiamento (coleção cadernos de políticas culturais; v. 3), Technical report, Ministério da Cultura.

Dickens, W. \& Katz, L. (1987), Inter-industry wage differences and theories of wage determination, Technical report, Working paper no. 2271, National Bureau of Economic Research, Cambridge.

Diniz, S. C. (2008), Análise do setor cultural nas regiões metropolitanas brasileiras, Technical report, Anais do XXXVI Encontro Nacional de Economia.

Diniz, S. C. (2009), Análise do consumo de bens e serviços artístico-culturais no Brasil metropolitano, Master's thesis, Universidade Federal de Minas Gerais.

Diniz, S. C. \& Machado, A. F. (2009), Análise do consumo de bens e serviços artístico-culturais no Brasil metropolitano, in 'Anais do VII ENABER - Encontro Nacional da Associação Brasileira de Estudos Regionais. São Paulo'.

Diniz, S. C. \& Machado, A. F. (2011), 'Analysis of the consumption of artisticcultural goods and services in brazil.', Journal of Cultural Economics 35, 1-18.

Ferreira Neto, A. B. (2008), Determinação do potencial de desenvolvimento cultural dos estados brasileiros, in 'Anais do VI ENABER - Encontro Nacional da Associação Brasileira de Estudos Regionais. Aracaju'.

Fields, J. \& Wolff, E. N. (1995), 'Interindustry wage differentials and the gender wage gap', Industrial and Labor Relations Review 49, 105-120.

Filer, R. K. (1986), 'The 'starving artist'-myth or reality? earnings of artists in the united state', Journal of Political Economy 94, 56-76.

Friedman, M. \& Savage, L. J. (1952), 'The expected-utility hypothesis and the measurability of utility', Journal of Political Economy 60(4).

Gatica, J., Mizala, A. \& Romaguerra, P. (1995), 'Interindustry wage differentials in brazil', Economic Development and Cultural Change 43(2), 315-31. 
Gibbons, R. \& Katz, L. R. (1992), 'Does unmeasured ability explain interindustry wage differentials?', Review of Economic Studies 59(3), 515-535.

Gittleman, M. \& Wollf, E. M. (1993), 'International comparisons of interindustry wage differentials', Review of Income and Wealth 39, 295-313.

Groshen, E. L. (1991), 'Five reasons why wages vary among emplyers', Industrial Relations 30(3), 351-381.

Heckman, J. J. (1979), 'Sample selection bias as a specification error', Econometrica $47,153-161$.

IBGE (2005), Sistema nacional de índices de preços ao consumidor: Estruturas de ponderação a partir das pesquisas de orçamentos familiares 20022003, in 'Série Relatórios Metodológicos'.

IPEA (2011), 'Deflator para pnad's'.

URL: <http://www.ipeadata.gov.br>

Jackubson, G. (1991), 'Estimation and testing of the union wage effect using panel data', The Review of Economic Studies 58(5), 971-991.

Jann, B. (2008), A stata implementation of the blinder-oaxaca decomposition, Technical Report 5, ETH Zurich Sociology, Working Paper.

Kahn, L. M. (1998), 'Collective bargaining and the inter-industry wage structure: international evidence', Economica 65, 507-534.

Keane, M. P. (1993), 'Individual heterogeneity and inter-industry wage differentials', Journal of Human Resources 28, 134-161.

Krueger, A. B. \& Summers, L. H. (1987), Reflections on inter-industry wage structure. in: Lang, k., leonard, j. (ed). unemployment and the structure of labor markets, basil blackwell, oxford, 1987., in 'Unemployment and the Structure of Labor Markets', Basil Blackwell, Oxford.

Krueger, A. B. \& Summers, L. H. (1988), 'Efficiency wges and the interindustry wage structure’, Econometrica 56, 259-293.

Langoni, C. G. (1973), Distribuição de renda e crescimento econômico no Brasil, Rio de Janeiro, Editora Expressão e Cultura.

Machado, A. F., Menezes, T. A. \& Diniz, S. C. (2010), 'Perfil dos consumidores de cinema no Brasil metropolitano.', VII ENABER - Encontro Nacional da Associação Brasileira de Estudos Regionais, Juiz de Fora.

Markusen, A. \& King, D. (2003), The Artistic Dividend: The Art's Hidden Contributions to Regional Development, Minneapolis: University of Minnesota.

Markusen, A., Wassal, G. H., Denatale, D. \& R., C. (2008), 'Definig the creative economy: Industry and occupational approaches', Economic Development Quarterly 22(1), 24-45.

Mendonça, R. P. B. \& R. (1995), Bem-estar, pobreza e desigualdade de renda:uma avaliação da evolução histórica e das disparidades regionais, Textos para discussão, IPEA. 
Menger, P. M. (1989), 'Rationalité et incertitude de la vie d'artiste', L’Année Sociologique 39, 111-151.

Mincer, J. (1974), Schooling, Experience and Earnings, National Bureau of Economic Research.

Moriconi, G. M. \& Marconi, N. (2008), Os salários dos professores públicos são atrativos no Brasil?, in 'Anais do XXXVI Encontro Nacional de Economia'.

Murphy, K. M. \& Topel, R. H. (1987), The evolution of unemployment in the united states: $1968-1985$, in 'NBER Macroeconomics Annual', Vol. 2, pp. 11-68.

Oaxaca, R. (1973), 'Male-female wage differentials in urban labor markets', International Economic Review 14, 693-709.

Pia, F. C., V.Feser \& M. (1996), 'Robustness properties of inequality measures.', Econometrica 64, 77-101.

Reis, A. C. F. (2002), Marketing Cultural e Financiamento da Cultura, São Paulo: Thomson Learning.

Reis, A. C. F. (2006), Economia da Cultura e Desenvolvimento Sustentável - o Caleidoscópio da cultura, São Paulo: Manole.

Resende, G. J. C. S. \& C., M. F. (2008), Eficácia dos controles de capitais no Brasil: abordagem teórica e empírica alternativa, in 'XIII Encontro Nacional de Economia Política'.

Santana, P. J. \& Menezes, T. A. (2008), 'Diferenças regionais nos determinantes dos gastos com cultura no brasil', VII ENABER - Encontro Nacional da Associação Brasileira de Estudos Regionais, São Paulo.

Shippen, B. S. (1999), 'Unmeasured skills in inter-industry wage differentials: evidence from the apparel industry', Journal of Labor Research 20, 161-169.

Teal, F. (1996), 'The size and sources of economic rent in developing country manufacturing labor market', Economic Journal 106(473), 963-976.

Throsby, D. (1992), Artists as workers, in 'Cultural Economics', Heidelberg: Springer-Verlag.

Throsby, D. (1994), A work preference model of artists' behaviour', in 'Cultural Economics and Cultural Policies', Kluwer Academic, Dordrecht, pp. 6980 .

Throsby, D. (2001), Economics and Culture, New York: Cambridge University Press.

Towse, R. (2003), A Handbook of Cultural Economics, Edward-Elgar.

Towse, R. (2006), Human capital and artists' labour markets, in 'Handbook of the Economics of Art and Culture', Vol. 1, Elsevier, Amsterdam.

Towse, R. \& Khakee, A. (1992), Cultural Economics, Heidelberg: SpringerVerlag. 
Valiati, L. (2008), 'Formação histórica de lugares de consumo e práticas culturais a partir da instalação de equipamentos culturais e sua relação com a informalidade econômica', VI ENABER - Encontro Nacional da Associação Brasileira de Estudos Regionais, Aracajú.

Valiati, L. \& Florissi, S. (2007), Economia da cultura: Bem-estar econômico evolução cultural, Porto Alegre: Editora da UFRGS.

Wassal, G. H. \& Alper, N. O. (1992), Towards a unified theory of the determinants of the earnings of artists, in 'Cultural Economics', Heidelberg: Springer-Verlag.

Wassal, G. H. \& Alper, N. O. (2006), Artists' careers and their labor markets, in 'Handbook of the Economics of Art and Culture', Vol. 1, Elsevier, Amsterdam.

Wetzels, C. (2008), 'Are workers in the cultural industries paid differently? wage differentials between three sub-industries of the cultural industries and their main industry: The case of netherlands', Journal of Cultural Economics 32(1), 59-77.

\section{Apêndice A}

Tabela A.1: Setores Culturais (CNAE) presentes na PNAD

\begin{tabular}{|c|c|}
\hline Código & Definição \\
\hline $22000^{*}$ & Edição, impressão e reprodução de gravações; \\
\hline 33004 & $\begin{array}{l}\text { Fabricação de aparelhos, instrumentos e materiais ópticos, fotográficos e } \\
\text { cinematográficos; }\end{array}$ \\
\hline 53062 & Comércio de livros, revistas e papelaria; \\
\hline $92011^{*}$ & Produção de filmes cinematográficos e fitas de vídeo; \\
\hline 92012 & Distribuição e projeção de filmes e de vídeos; \\
\hline $92013^{*}$ & Atividades de rádio; \\
\hline $92014^{*}$ & Atividades de televisão; \\
\hline $92015^{*}$ & Outras atividades artísticas e de espetáculos; \\
\hline 92020 & Atividades de agências de notícias; \\
\hline $92030^{*}$ & Bibliotecas, arquivos, museus e outras atividades culturais; \\
\hline 92040 & Atividades desportivas e outras relacionadas ao lazer; \\
\hline 71030 & Aluguel de objetos pessoais e domésticos; e \\
\hline 74030 & Publicidade. \\
\hline
\end{tabular}

Nota: Em cinza estão selecionados os considerados artistas.

Fonte: Elaboração própria a partir da PNAD.

* são os considerados artistas 
Tabela A.2: Ocupações Culturais (CBO) presentes na PNAD

\begin{tabular}{|c|c|}
\hline Código & Definição \\
\hline 2330 & $\begin{array}{l}\text { Professores e instrutores (com formação de nível superior) no ensino pro- } \\
\text { fissional; }\end{array}$ \\
\hline 2531 & Profissionais de marketing, publicidade e comercialização; \\
\hline 2611 & Profissionais do jornalismo; \\
\hline 2612 & Profissionais da informação; \\
\hline 2613 & Arquivologistas e museólogos; \\
\hline 2614 & Filólogos, tradutores e intérpretes; \\
\hline $2615^{*}$ & Escritores e redatores; \\
\hline 2616 & Especialistas em editoração; \\
\hline $2617^{*}$ & Locutores e comentaristas; \\
\hline 2621 & Produtores de espetáculos; \\
\hline $2622^{*}$ & Coreógrafos e bailarinos; \\
\hline $2623^{*}$ & Atores, diretores de espetáculos e afins; \\
\hline $2624^{*}$ & Compositores, músicos e cantores; \\
\hline $2625^{*}$ & $\begin{array}{l}\text { Desenhistas industriais (designer), escultores, pintores e afins (inclui o } \\
\text { artesão); }\end{array}$ \\
\hline 2627 & Decoradores de interiores e cenógrafos; \\
\hline 3313 & Professores (com formação de nível médio) no ensino profissionalizante; \\
\hline 3322 & Professores leigos no ensino profissionalizante; \\
\hline 3331 & Instrutores e professores de escolas livres; \\
\hline 3524 & Agentes de fiscalização de espetáculos e meios de comunicação; \\
\hline 3544 & Leiloeiros e avaliadores; \\
\hline 3711 & Técnicos em biblioteconomia; \\
\hline 3712 & Técnicos em museologia; \\
\hline 3713 & Técnicos em artes gráficas; \\
\hline $3721^{*}$ & Cinegrafistas; \\
\hline $3722^{*}$ & Fotógrafos; \\
\hline 3723 & Técnicos em operações de máquinas de transmissão de dados; \\
\hline 3731 & Técnicos em operação de estação de rádio; \\
\hline 3732 & Técnicos em operação de estação de televisão; \\
\hline 3741 & Técnicos em operação de aparelhos de sonorização; \\
\hline 3742 & Técnicos em operação de aparelhos de cenogra?a; \\
\hline 3743 & Técnicos em operação de aparelhos de projeção; \\
\hline 3751 & Decoradores e vitrinistas de nível médio; \\
\hline $3761^{*}$ & Bailarinos de danças populares; \\
\hline $3762^{*}$ & Músicos e cantores populares; \\
\hline $3763^{*}$ & Palhaços, acrobatas e afins; \\
\hline $3764^{*}$ & Apresentadores de espetáculos; \\
\hline $3765^{*}$ & Modelos; \\
\hline 4151 & Escriturários de serviços de biblioteca e documentação; \\
\hline $7421^{*}$ & Confeccionadores de instrumentos musicais; \\
\hline 7501 & Supervisores de joalheria e afins; \\
\hline 7502 & Supervisores de vidraria, cerâmica e afins; \\
\hline $7519^{*}$ & Joalheiros e artesãos de metais preciosos e semipreciosos; \\
\hline 7521 & Sopradores e moldadores de vidro e afins; \\
\hline 7522 & Cortadores, polidores, jateadores e gravadores de vidros e afins; \\
\hline 7523 & Ceramistas (preparação e fabricação); \\
\hline 7524 & Vidreiros e ceramistas (acabamento e decoração); \\
\hline
\end{tabular}

Nota: Em cinza estão selecionados os considerados artistas.

Fonte: Elaboração própria a partir da PNAD.

* são os considerados artistas 
Tabela A.2: Ocupações Culturais (CBO) presentes na PNAD (continuação)

\begin{tabular}{ll}
\hline 7606 & Supervisores das artes gráficas; \\
7611 & Trabalhadores da preparação da tecelagem; \\
7612 & Operadores da preparação da tecelagem; \\
7613 & Operadores de tear e máquinas similares; \\
7660 & Trabalhadores polivalentes das artes gráficas; \\
7661 & Trabalhadores da pré impressão gráfica \\
7662 & Trabalhadores da impressão gráfica; \\
7663 & Trabalhadores do acabamento gráfico; \\
7664 & Trabalhadores de laboratório fotográfico; \\
$7681^{*}$ & Trabalhadores artesanais da tecelagem; \\
$7682^{*}$ & Trabalhadores artesanais da confecção de roupas; \\
$7683^{*}$ & Trabalhadores artesanais da confecção de calçados e artefatos de couros \\
& e peles; \\
7686 & Trabalhadores tipográficos, linotipistas e afins; \\
7687 & Encadernadores e recuperadores de livros (pequenos lotes ou a unidade); \\
9152 & Reparadores de instrumentos musicais; e \\
9912 & Mantenedores de equipamentos de lazer. \\
\hline
\end{tabular}

Nota: Em cinza estão selecionados os considerados artistas.

Fonte: Elaboração própria a partir da PNAD. 
Tabela A.3: Descrição das variáveis

\begin{tabular}{|c|c|}
\hline Variable & Definiçãa \\
\hline Lw & logarítimo natural da renda real por horas trabalhadas \\
\hline Idade & idade do indivíduo \\
\hline idade 2 & idade do indivíduo elevada ao quadrado \\
\hline estudo & anos estudados por cada indivíduo \\
\hline $\exp$ & anos trabalhados por cada indivíduo \\
\hline $\exp 2$ & experiência (exp) do indivíduo elevada ao quadrado \\
\hline dfem & valor "1" para mulheres e "0" para homens \\
\hline dindio & valor "1" para índios e "0" para outras raças \\
\hline dpardo & valor "1" para pardos e "0" para outras raças \\
\hline damarelo & valor "1" para ind. da raça amarela e "0" para outras raças \\
\hline dnegro & valor "1" para negros e "0" para outras raças \\
\hline dbranco & valor "1" para brancos e "0" para outras raças \\
\hline dcult & $\begin{array}{l}\text { valor "1" para trabalhadores do setor cultural e "0" para outros } \\
\text { setores }\end{array}$ \\
\hline dart & valor "1" para artistas e "0" para outras trabalhadores \\
\hline dfun & $\begin{array}{l}\text { valor "1" para condição de funcionário e "0" para outras condição } \\
\text { de ocupação }\end{array}$ \\
\hline dcp & $\begin{array}{l}\text { valor "1" para condição de conta própria e "0" para outras condi- } \\
\text { ção de ocupação }\end{array}$ \\
\hline demp & $\begin{array}{l}\text { valor "1" para condição de empregador e "0" para outras condição } \\
\text { de ocupação }\end{array}$ \\
\hline dcultcp & $\begin{array}{l}\text { valor "1" para condição de conta própria no setor cultual e "0" } \\
\text { para demais }\end{array}$ \\
\hline dcultfun & $\begin{array}{l}\text { valor "1" para condição de funcionário no setor cultural e "0" para } \\
\text { demais }\end{array}$ \\
\hline dcultemp & $\begin{array}{l}\text { valor "1" para condição de empregador no setor cultural e "0" } \\
\text { para demais }\end{array}$ \\
\hline dartcp & $\begin{array}{l}\text { valor " } 1 \text { " para condição de conta própria e artista e "0" para de- } \\
\text { mais }\end{array}$ \\
\hline dartfun & valor "1" para condição de funcionário e artista e "0" para demais \\
\hline dartemp & valor "1" para condição de empregador e artista e "0" para demais \\
\hline $\mathrm{duf}^{*}$ & duf1 a duf27 valor "1" se pertence à UF e "0" caso contrário \\
\hline dyr $r^{*}$ & $\begin{array}{l}\text { dyr1 a dyr6 valor "1" se pertence ano da PNAD e "0" caso contrá- } \\
\text { rio }\end{array}$ \\
\hline coorte & $\begin{array}{l}\text { variável categórica associada ao ano de nascimento, a cada } 5 \text { anos } \\
\text { uma coorte }\end{array}$ \\
\hline $\mathrm{dco}^{*}$ & dco1 a dco1 2 valor " 1 " se pertence à coorte e "0" caso contrário \\
\hline $\operatorname{Pr}$ & $\begin{array}{l}\text { valor " } 1 \text { " se está inserido no mercado de trabalho e " } 0 \text { " caso con- } \\
\text { trário }\end{array}$ \\
\hline chefe & valor "1" para condição de chefe do domicílio e "0" caso contrário \\
\hline conj & $\begin{array}{l}\text { valor "1" para condição de conjuge do domicílio e "0" caso contrá- } \\
\text { rio }\end{array}$ \\
\hline filho & valor "1" para condição de filho na família e "0" caso contrário \\
\hline child05 & $\begin{array}{l}\text { valor " } 1 \text { " se há criança entre } 0 \text { e } 5 \text { anos no domicílio e "0" caso } \\
\text { contrário }\end{array}$ \\
\hline
\end{tabular}


Tabela A.4: Análise descritiva das variáveis

\begin{tabular}{|c|c|c|c|c|c|}
\hline Variável & Obs & Média & Desv. Pad. & Min & Max \\
\hline idade & 1027218 & 35,905 & 12,203 & 16 & 65 \\
\hline horas & 1027218 & 40,512 & 14,514 & 1 & 99 \\
\hline $\exp$ & 1027218 & 7,044 & 8,650 & 0 & 60 \\
\hline estudo & 1027218 & 8,593 & 4,437 & 1 & 17 \\
\hline dfun & 1027218 & 0,317 & 0,465 & 0 & 1 \\
\hline dcp & 1027218 & 0,218 & 0,413 & 0 & 1 \\
\hline demp & 1027218 & 0,040 & 0,196 & 0 & 1 \\
\hline wr & 1027218 & 765,931 & 1411,454 & 0 & 215541 \\
\hline wrh & 1027218 & 5,131 & 15,154 & 0 & 3750 \\
\hline dfem & 1027218 & 0,574 & 0,494 & 0 & 1 \\
\hline dbranca & 1027218 & 0,480 & 0,500 & 0 & 1 \\
\hline dindio & 1027218 & 0,003 & 0,052 & 0 & 1 \\
\hline dnegro & 1027218 & 0,072 & 0,259 & 0 & 1 \\
\hline dpardo & 1027218 & 0,441 & 0,497 & 0 & 1 \\
\hline damarelo & 1027218 & 0,004 & 0,063 & 0 & 1 \\
\hline dcult & 1027218 & 0,005 & 0,072 & 0 & 1 \\
\hline dart & 1027218 & 0,002 & 0,040 & 0 & 1 \\
\hline dco1 & 1027218 & 0,011 & 0,106 & 0 & 1 \\
\hline dco 2 & 1027218 & 0,009 & 0,096 & 0 & 1 \\
\hline dco3 & 1027218 & 0,032 & 0,175 & 0 & 1 \\
\hline dco 4 & 1027218 & 0,053 & 0,224 & 0 & 1 \\
\hline dco5 & 1027218 & 0,077 & 0,267 & 0 & 1 \\
\hline dco6 & 1027218 & 0,100 & 0,300 & 0 & 1 \\
\hline dco 7 & 1027218 & 0,121 & 0,326 & 0 & 1 \\
\hline $\mathrm{d} \operatorname{co} 8$ & 1027218 & 0,129 & 0,336 & 0 & 1 \\
\hline dco 9 & 1027218 & 0,133 & 0,339 & 0 & 1 \\
\hline dco10 & 1027218 & 0,142 & 0,349 & 0 & 1 \\
\hline dco11 & 1027218 & 0,133 & 0,339 & 0 & 1 \\
\hline dco12 & 1027218 & 0,060 & 0,237 & 0 & 1 \\
\hline dcultcp & 1027218 & 0,002 & 0,043 & 0 & 1 \\
\hline dcultfun & 1027218 & 0,002 & 0,044 & 0 & 1 \\
\hline dcultemp & 1027218 & 0 & 0,011 & 0 & 1 \\
\hline dartcp & 1027218 & 0,001 & 0,030 & 0 & 1 \\
\hline dartfun & 1027218 & 0 & 0,014 & 0 & 1 \\
\hline dartemp & 1027218 & 0 & 0,006 & 0 & 1 \\
\hline
\end{tabular}


Tabela A.5: Regressões completas para o setor cultural

\begin{tabular}{|c|c|c|c|c|}
\hline Var. & $\begin{array}{l}-1 \\
\text { lw }\end{array}$ & $\begin{array}{l}-2 \\
\mathrm{Lw}\end{array}$ & $\begin{array}{l}-3 \\
1 w\end{array}$ & $\begin{array}{c}-4 \\
1 \mathrm{w}\end{array}$ \\
\hline dcult & $\begin{array}{l}0.260^{* * *} \\
(0.0255)\end{array}$ & & $\begin{array}{l}0.261^{* * *} \\
(0.0255)\end{array}$ & $\begin{array}{l}0.259^{* * *} \\
(0.0255)\end{array}$ \\
\hline $\exp$ & $\begin{array}{l}0.0296^{* * *} \\
(0.000289)\end{array}$ & $\begin{array}{l}0.0354^{* * *} \\
(0.00508)\end{array}$ & $\begin{array}{l}0.0295^{* * *} \\
(0.000289)\end{array}$ & $\begin{array}{l}0.0300^{* * *} \\
(0.000288)\end{array}$ \\
\hline $\exp 2$ & $\begin{array}{c}-0.000638^{* * *} \\
(9.63 e-06)\end{array}$ & $\begin{array}{c}-0.000762^{* * *} \\
(0.000177)\end{array}$ & $\begin{array}{c}-0.000638^{* * *} \\
(9.63 e-06)\end{array}$ & $\begin{array}{c}-0.000653^{* * *} \\
(9.61 e-06)\end{array}$ \\
\hline estudo & $\begin{array}{l}0.105^{* * *} \\
(0.000221)\end{array}$ & $\begin{array}{l}0.0818^{* * *} \\
(0.00422)\end{array}$ & $\begin{array}{l}0.105^{* * *} \\
(0.000221)\end{array}$ & $\begin{array}{l}0.104^{* * *} \\
(0.000222)\end{array}$ \\
\hline idade & $\begin{array}{l}0.0620^{* * *} \\
(0.000438)\end{array}$ & $\begin{array}{l}0.0701^{* * *} \\
(0.00822)\end{array}$ & $\begin{array}{l}0.0609^{* * *} \\
(0.000439)\end{array}$ & $\begin{array}{l}0.0619^{* * *} \\
(0.00107)\end{array}$ \\
\hline idade2 & $\begin{array}{c}-0.000591^{* * *} \\
(5.83 e-06)\end{array}$ & $\begin{array}{c}-0.000748^{* * *} \\
(0.000113)\end{array}$ & $\begin{array}{c}-0.000582^{* * *} \\
(5.84 e-06)\end{array}$ & $\begin{array}{c}-0.000621^{* * *} \\
(1.54 e-05)\end{array}$ \\
\hline dfem & $\begin{array}{l}0.238^{* * *} \\
(0.00170)\end{array}$ & $\begin{array}{l}0.0886^{* * *} \\
(0.0306)\end{array}$ & $\begin{array}{l}0.219^{* * *} \\
(0.00173)\end{array}$ & $\begin{array}{l}0.208^{* * *} \\
(0.00190)\end{array}$ \\
\hline dindio & $\begin{array}{c}-0.0949^{* * *} \\
(0.0161)\end{array}$ & $\begin{array}{l}0.0135 \\
(0.204)\end{array}$ & $\begin{array}{c}-0.0982^{* * *} \\
(0.0161)\end{array}$ & $\begin{array}{c}-0.114^{* * *} \\
(0.0161)\end{array}$ \\
\hline dnegro & $\begin{array}{c}-0.126^{* * *} \\
(0.00313)\end{array}$ & $\begin{array}{c}-0.188^{* * *} \\
(0.0579)\end{array}$ & $\begin{array}{c}-0.127^{* * *} \\
(0.00313)\end{array}$ & $\begin{array}{c}-0.135^{* * *} \\
(0.00312)\end{array}$ \\
\hline dpardo & $\begin{array}{c}-0.123^{* * *} \\
(0.00182)\end{array}$ & $\begin{array}{c}-0.158^{* * *} \\
(0.0286)\end{array}$ & $\begin{array}{c}-0.124^{* * *} \\
(0.00182)\end{array}$ & $\begin{array}{c}-0.126^{* * *} \\
(0.00182)\end{array}$ \\
\hline damarelo & $\begin{array}{l}0.119^{* * *} \\
(0.0142)\end{array}$ & $\begin{array}{r}-0.122 \\
(0.182)\end{array}$ & $\begin{array}{l}0.119^{* * *} \\
(0.0141)\end{array}$ & $\begin{array}{l}0.115^{* * *} \\
(0.0142)\end{array}$ \\
\hline dfun & $\begin{array}{l}0.107^{* * *} \\
(0.00174)\end{array}$ & $\begin{array}{r}0.0212 \\
(0.0315)\end{array}$ & $\begin{array}{l}0.105^{* * *} \\
(0.00174)\end{array}$ & $\begin{array}{l}0.0985^{* * *} \\
(0.00174)\end{array}$ \\
\hline dcp & $\begin{array}{c}-0.0834^{* * *} \\
(0.00248)\end{array}$ & $\begin{array}{l}0.191^{* * *} \\
(0.0384)\end{array}$ & $\begin{array}{c}-0.0827^{* * *} \\
(0.00248)\end{array}$ & $\begin{array}{c}-0.0874^{* * *} \\
(0.00248)\end{array}$ \\
\hline demp & $\begin{array}{l}0.595^{* * *} \\
(0.00511)\end{array}$ & $\begin{array}{l}0.722^{* * *} \\
(0.0995)\end{array}$ & $\begin{array}{l}0.594^{* * *} \\
(0.00511)\end{array}$ & $\begin{array}{l}0.591^{* * *} \\
(0.00509)\end{array}$ \\
\hline dcultcp & $\begin{array}{l}0.264^{* * *} \\
(0.0365)\end{array}$ & & $\begin{array}{l}0.264^{* * *} \\
(0.0364)\end{array}$ & $\begin{array}{l}0.265^{* * *} \\
(0.0364)\end{array}$ \\
\hline dcultfun & $\begin{array}{c}-0.109^{* * *} \\
(0.0298)\end{array}$ & & $\begin{array}{c}-0.109^{* * *} \\
(0.0298)\end{array}$ & $\begin{array}{c}-0.107^{* * *} \\
(0.0298)\end{array}$ \\
\hline dcultemp & $\begin{array}{l}0.0996 \\
(0.101)^{* * *}\end{array}$ & & $\begin{array}{l}0.100 \\
(0.102)\end{array}$ & $\begin{array}{l}0.0935 \\
(0.101)_{* * *}\end{array}$ \\
\hline duf1 & $\begin{array}{c}-0.0442^{* * *} \\
(0.00640)\end{array}$ & $\begin{array}{l}-0.389^{* * *} \\
(0.101)\end{array}$ & $\begin{array}{c}-0.0455^{* * *} \\
(0.00640)\end{array}$ & $\begin{array}{c}-0.0495^{* * *} \\
(0.00637)\end{array}$ \\
\hline duf2 & $\begin{array}{c}-0.127^{* * *} \\
(0.00857)\end{array}$ & $\begin{array}{l}-0.257^{* *} \\
(0.127)\end{array}$ & $\begin{array}{c}-0.129^{* * *} \\
(0.00858)\end{array}$ & $\begin{array}{c}-0.138^{* * *} \\
(0.00856)\end{array}$ \\
\hline duf3 & $\begin{array}{c}-0.126^{* * *} \\
(0.00521)\end{array}$ & $\begin{array}{c}-0.0671 \\
(0.102)\end{array}$ & $\begin{array}{c}-0.128^{* * *} \\
(0.00521)\end{array}$ & $\begin{array}{c}-0.133^{* * *} \\
(0.00519)\end{array}$ \\
\hline duf4 & $\begin{array}{c}-0.0483^{* * *} \\
(0.0114)\end{array}$ & $\begin{array}{r}-0.133 \\
(0.161)\end{array}$ & $\begin{array}{c}-0.0498^{* * *} \\
(0.0114)\end{array}$ & $\begin{array}{c}-0.0568^{* * *} \\
(0.0114)\end{array}$ \\
\hline duf5 & $\begin{array}{c}-0.213^{* * *} \\
(0.00418)\end{array}$ & $\begin{array}{c}-0.270^{* * *} \\
(0.0770)\end{array}$ & $\begin{array}{c}-0.215^{* * *} \\
(0.00418)\end{array}$ & $\begin{array}{c}-0.221^{* * *} \\
(0.00416)\end{array}$ \\
\hline duf6 & $\begin{array}{r}-0.0147 \\
(0.00950)\end{array}$ & $\begin{array}{c}-0.0804 \\
(0.166)\end{array}$ & $\begin{array}{c}-0.0164^{*} \\
(0.00950)\end{array}$ & $\begin{array}{c}-0.0235^{* *} \\
(0.00949)\end{array}$ \\
\hline duf7 & $\begin{array}{r}-0.271^{* * *} \\
(0.00661)\end{array}$ & $\begin{array}{c}-0.316^{*} \\
(0.163)\end{array}$ & $\begin{array}{c}-0.272^{* * *} \\
(0.00661)\end{array}$ & $\begin{array}{c}-0.276^{* * *} \\
(0.00659)\end{array}$ \\
\hline duf8 & $\begin{array}{r}-0.568^{* * *} \\
(0.00773)\end{array}$ & $\begin{array}{c}-0.503^{* * *} \\
(0.0970)\end{array}$ & $\begin{array}{c}-0.568^{* * *} \\
(0.00773)\end{array}$ & $\begin{array}{c}-0.571^{* * *} \\
(0.00770)\end{array}$ \\
\hline duf9 & $\begin{array}{c}-0.689^{* * *} \\
(0.00864)\end{array}$ & $\begin{array}{c}-0.561^{* * *} \\
(0.112)\end{array}$ & $\begin{array}{c}-0.688^{* * *} \\
(0.00863)\end{array}$ & $\begin{array}{c}-0.696^{* * *} \\
(0.00863)\end{array}$ \\
\hline duf10 & $\begin{array}{c}-0.593^{* * *} \\
(0.00439)\end{array}$ & $\begin{array}{c}-0.394^{* * *} \\
(0.0640)\end{array}$ & $\begin{array}{c}-0.594^{* * *} \\
(0.00438)\end{array}$ & $\begin{array}{c}-0.597^{* * *} \\
(0.00438)\end{array}$ \\
\hline duf11 & $\begin{array}{c}-0.395^{* * *} \\
(0.00676)\end{array}$ & $\begin{array}{c}-0.441^{* * *} \\
(0.103)\end{array}$ & $\begin{array}{c}-0.395^{* * *} \\
(0.00676)\end{array}$ & $\begin{array}{c}-0.399^{* * *} \\
(0.00673)\end{array}$ \\
\hline duf12 & $\begin{array}{r}-0.418^{* * *} \\
(0.00627)\end{array}$ & $\begin{array}{c}-0.315^{* * *} \\
(0.112)\end{array}$ & $\begin{array}{c}-0.418^{* * *} \\
(0.00627)\end{array}$ & $\begin{array}{c}-0.423^{* * *} \\
(0.00625)\end{array}$ \\
\hline duf13 & $\begin{array}{c}-0.466^{* * *} \\
(0.00420)\end{array}$ & $\begin{array}{c}-0.421^{* * *} \\
(0.0575)\end{array}$ & $\begin{array}{c}-0.467^{* * *} \\
(0.00420)\end{array}$ & $\begin{array}{c}-0.470^{* * *} \\
(0.00420)\end{array}$ \\
\hline duf14 & $\begin{array}{c}-0.402^{* * *} \\
(0.00724)\end{array}$ & $\begin{array}{c}-0.0843 \\
(0.185)\end{array}$ & $\begin{array}{c}-0.402^{* * *} \\
(0.00725)\end{array}$ & $\begin{array}{c}-0.405^{* * *} \\
(0.00722)\end{array}$ \\
\hline duf15 & $\begin{array}{c}-0.332^{* * *} \\
(0.00641)\end{array}$ & $\begin{array}{c}-0.325^{* * *} \\
(0.110)\end{array}$ & $\begin{array}{c}-0.332^{* * *} \\
(0.00641)\end{array}$ & $\begin{array}{c}-0.334^{* * *} \\
(0.00638)\end{array}$ \\
\hline duf16 & $\begin{array}{c}-0.388^{* * *} \\
(0.00344)\end{array}$ & $\begin{array}{c}-0.352^{* * *} \\
(0.0586)\end{array}$ & $\begin{array}{c}-0.389^{* * *} \\
(0.00343)\end{array}$ & $\begin{array}{c}-0.391^{* * *} \\
(0.00342)\end{array}$ \\
\hline
\end{tabular}

Nota: Erros padrões robustos em parêntesis ${ }^{* * *} \mathrm{p}<0,01$, ${ }^{* *} \mathrm{p}<0,05$, $^{*} \mathrm{p}<0,1$.

Fonte: Resultado da pesquisa. 
Tabela A.5: Regressões completas para o setor cultural (continuação)

\begin{tabular}{|c|c|c|c|c|}
\hline Var. & $\begin{array}{l}-1 \\
\operatorname{lw}\end{array}$ & $\begin{array}{c}-2 \\
\mathrm{Lw}\end{array}$ & $\begin{array}{l}-3 \\
1 w\end{array}$ & $\begin{array}{l}-4 \\
\operatorname{lw}\end{array}$ \\
\hline duf17 & $\begin{array}{c}-0.245^{* * *} \\
(0.00295)\end{array}$ & $\begin{array}{c}-0.222^{* * *} \\
(0.0489)\end{array}$ & $\begin{array}{c}-0.244^{* * *} \\
(0.00295)\end{array}$ & $\begin{array}{c}-0.245^{* * *} \\
(0.00294)\end{array}$ \\
\hline duf18 & $\begin{array}{r}-0.206^{* * *} \\
(0.00555)\end{array}$ & $\begin{array}{c}-0.335^{* * *} \\
(0.0852)\end{array}$ & $-0.206^{* * *}$ & $\begin{array}{r}-0.207^{* * *} \\
(0.00551)\end{array}$ \\
\hline duf19 & $\begin{array}{c}-0.0727^{* * *} \\
(0.00338)\end{array}$ & $\begin{array}{c}-2.42 e-05 \\
(0.0479)\end{array}$ & $\begin{array}{c}-0.0727^{* * *} \\
(0.00338)\end{array}$ & $\begin{array}{r}-0.0717^{* * *} \\
(0.00336)\end{array}$ \\
\hline duf 21 & $\begin{array}{c}-0.149^{* * *} \\
(0.00362)\end{array}$ & $\begin{array}{c}-0.139^{* * *} \\
(0.0497)\end{array}$ & $\begin{array}{c}-0.150^{* * *} \\
(0.00362)\end{array}$ & $\begin{array}{r}-0.151^{* * *} \\
(0.00360)\end{array}$ \\
\hline duf 22 & $\begin{array}{c}-0.0518^{* * *} \\
(0.00426)\end{array}$ & $\begin{array}{c}-0.208^{* * *} \\
(0.0711)\end{array}$ & $\begin{array}{c}-0.0522^{* * *} \\
(0.00425)\end{array}$ & $\begin{array}{c}-0.0519^{* * *} \\
(0.00424)\end{array}$ \\
\hline duf 23 & $\begin{array}{c}-0.157^{* * *} \\
(0.00331)\end{array}$ & $\begin{array}{c}-0.231^{* * *} \\
(0.0449)\end{array}$ & $\begin{array}{c}-0.157^{* * *} \\
(0.00330)\end{array}$ & $\begin{array}{c}-0.157^{* * *} \\
(0.00329)\end{array}$ \\
\hline duf 24 & $\begin{array}{c}-0.1411^{* * *} \\
(0.00514)\end{array}$ & $\begin{array}{r}-0.178^{* *} \\
(0.0762)\end{array}$ & $\begin{array}{r}-0.142^{* * *} \\
(0.00514)\end{array}$ & $\begin{array}{r}-0.144^{* * *} \\
(0.00511)\end{array}$ \\
\hline duf 25 & $\begin{array}{c}-0.0232^{* * *} \\
(0.00503)\end{array}$ & $\begin{array}{r}0.0661 \\
(0.0976)\end{array}$ & $\begin{array}{c}-0.0245^{* * *} \\
(0.00503)\end{array}$ & $\begin{array}{c}-0.0261^{* * *} \\
(0.00501)\end{array}$ \\
\hline duf 26 & $\begin{array}{c}-0.151^{* * *} \\
(0.00378)\end{array}$ & $\begin{array}{r}-0.0791 \\
(0.0560)\end{array}$ & $\begin{array}{c}-0.152^{* * *} \\
(0.00378)\end{array}$ & $\begin{array}{c}-0.155^{* * *} \\
(0.00376)\end{array}$ \\
\hline duf 27 & $\begin{array}{l}0.221^{* * *} \\
(0.00497)\end{array}$ & $\begin{array}{l}0.256^{* * *} \\
(0.0686)\end{array}$ & $\begin{array}{l}0.220^{* * *} \\
(0.00497)\end{array}$ & $\begin{array}{l}0.216^{* * *} \\
(0.00495)\end{array}$ \\
\hline dyr 2 & & & & $\begin{array}{r}-0.0719^{* * *} \\
(0.00285)\end{array}$ \\
\hline dyr3 & & & & $\begin{array}{c}-0.0642^{* * *} \\
(0.00283)\end{array}$ \\
\hline dyr 4 & & & & $\begin{array}{c}-0.0228^{* * *} \\
(0.00288)\end{array}$ \\
\hline dyr 5 & & & & $\begin{array}{l}0.0374^{* * *} \\
(0.00297)\end{array}$ \\
\hline dyr6 & & & & $\begin{array}{l}0.0813^{* * *} \\
(0.00313)\end{array}$ \\
\hline $\mathrm{dco} 2$ & & & & $\begin{array}{l}0.172^{* * *} \\
(0.0207)\end{array}$ \\
\hline $\mathrm{dco} 3$ & & & & $\begin{array}{l}0.159^{* * *} \\
(0.0160)\end{array}$ \\
\hline dco 4 & & & & $\begin{array}{l}0.115^{* * *} \\
(0.0127)\end{array}$ \\
\hline dco5 & & & & $\begin{array}{l}0.0829^{* * *} \\
(0.0104)\end{array}$ \\
\hline dco 6 & & & & $\begin{array}{l}0.0485^{* * *} \\
(0.00883)\end{array}$ \\
\hline $\mathrm{dco} 7$ & & & & $\begin{array}{l}0.0360 \\
(0.00775)\end{array}$ \\
\hline $\mathrm{dco} 8$ & & & & $\begin{array}{l}0.0533^{* * *} \\
(0.00684)\end{array}$ \\
\hline $\mathrm{d} \operatorname{co} 9$ & & & & $\begin{array}{l}0.0861^{* * *} \\
(0.00585)\end{array}$ \\
\hline $\mathrm{d} \operatorname{co} 10$ & & & & $\begin{array}{l}0.0852^{* * *} \\
(0.00463)\end{array}$ \\
\hline $\mathrm{dco} 11$ & & & & $\begin{array}{l}0.0276^{* * *} \\
(0.00363)\end{array}$ \\
\hline lambda & & & & $\begin{array}{c}-0.278^{* * *} \\
(0.00839)\end{array}$ \\
\hline Constant & $-1.192^{* * *}$ & $\begin{array}{c}-0.680^{* * *} \\
(0.149)\end{array}$ & $-1.128^{* * *}$ & $-1.129^{* * *}$ \\
\hline Observations & 937,721 & 5,349 & $1,027,218$ & 937,721 \\
\hline R-squared & 0.460 & 0.280 & & 0.465 \\
\hline
\end{tabular}

Nota: Erros padrões robustos em parêntesis ${ }^{* * *} \mathrm{p}<0,01,{ }^{* *} \mathrm{p}<0,05,{ }^{*} \mathrm{p}<0,1$.

Fonte: Resultado da pesquisa. 
Tabela A.6: Regressões completas para os artistas

\begin{tabular}{|c|c|c|c|c|}
\hline Var. & $\begin{array}{l}-5 \\
1 w\end{array}$ & $\begin{array}{l}-6 \\
1 w\end{array}$ & $\begin{array}{l}-7 \\
\text { lw }\end{array}$ & $\begin{array}{l}-8 \\
1 w\end{array}$ \\
\hline dart & $\begin{array}{l}0.562^{* * *} \\
(0.0481)\end{array}$ & & $\begin{array}{l}0.562^{* * *} \\
(0.0479)\end{array}$ & $\begin{array}{l}0.558^{* * *} \\
(0.0485)\end{array}$ \\
\hline $\exp$ & $\begin{array}{l}0.0295^{* * *} \\
(0.000289)\end{array}$ & $\begin{array}{l}0.0376^{* * *} \\
(0.00958)\end{array}$ & $\begin{array}{l}0.0295^{* * *} \\
(0.000289)\end{array}$ & $\begin{array}{l}0.0299^{* * *} \\
(0.000288)\end{array}$ \\
\hline $\exp 2$ & $\begin{array}{c}-0.000638^{* * *} \\
(9.63 e-06)\end{array}$ & $\begin{array}{c}-0.000892^{* * *} \\
(0.000289)\end{array}$ & $\begin{array}{c}-0.000638^{* * *} \\
(9.63 e-06)\end{array}$ & $\begin{array}{c}-0.000653^{* * *} \\
(9.61 e-06)\end{array}$ \\
\hline estudo & $\begin{array}{l}0.105^{* * *} \\
(0.000221)\end{array}$ & $\begin{array}{l}0.0596^{* * *} \\
(0.00880)\end{array}$ & $\begin{array}{l}0.105^{* * *} \\
(0.000221)\end{array}$ & $\begin{array}{l}0.104^{* * *} \\
(0.000222)\end{array}$ \\
\hline idade & $\begin{array}{l}0.0620^{* * *} \\
(0.000438)\end{array}$ & $\begin{array}{l}0.0558^{* * *} \\
(0.0154)\end{array}$ & $\begin{array}{l}0.0610^{* * *} \\
(0.000439)\end{array}$ & $\begin{array}{l}0.0619^{* * *} \\
(0.00107)\end{array}$ \\
\hline idade2 & $\begin{array}{l}-0.000591^{* * *} \\
(5.83 e-06)\end{array}$ & $\begin{array}{c}-0.000631^{* * *} \\
(0.000204)\end{array}$ & $\begin{array}{c}-0.000583^{* * *} \\
(5.84 e-06)\end{array}$ & $\begin{array}{l}-0.000622^{* * *} \\
(1.54 e-05)\end{array}$ \\
\hline dfem & $\begin{array}{l}0.239^{* * *} \\
(0.00170)\end{array}$ & $\begin{array}{l}0.235^{* * *} \\
(0.0652)\end{array}$ & $\begin{array}{l}0.220^{* * *} \\
(0.00173)\end{array}$ & $\begin{array}{l}0.208^{* * *} \\
(0.00190)\end{array}$ \\
\hline dindio & $\begin{array}{c}-0.0946^{* * *} \\
(0.0161)\end{array}$ & $\begin{array}{l}0.169 \\
(0.397)\end{array}$ & $\begin{array}{c}-0.0979^{* * *} \\
(0.0161)\end{array}$ & $\begin{array}{l}-0.114^{* * *} \\
(0.0161)\end{array}$ \\
\hline dnegro & $\begin{array}{c}-0.126^{* * *} \\
(0.00313)\end{array}$ & $\begin{array}{c}-0.235^{* *} \\
(0.103)\end{array}$ & $\begin{array}{c}-0.127^{* * *} \\
(0.00313)\end{array}$ & $\begin{array}{c}-0.135^{* * *} \\
(0.00312)\end{array}$ \\
\hline dpardo & $\begin{array}{c}-0.123^{* * *} \\
(0.00182)\end{array}$ & $\begin{array}{c}-0.195^{* * *} \\
(0.0604)\end{array}$ & $\begin{array}{c}-0.124^{* * *} \\
(0.00182)\end{array}$ & $\begin{array}{c}-0.126^{* * *} \\
(0.00182)\end{array}$ \\
\hline damarelo & $\begin{array}{l}0.119^{* * *} \\
(0.0142)\end{array}$ & $\begin{array}{l}0.0430 \\
(0.231)\end{array}$ & $\begin{array}{l}0.119^{* * *} \\
(0.0141)\end{array}$ & $\begin{array}{l}0.115^{\star * *} \\
(0.0142)\end{array}$ \\
\hline dfun & $\begin{array}{l}0.107^{* * *} \\
(0.00173)\end{array}$ & $\begin{array}{r}0.0155 \\
(0.0752)\end{array}$ & $\begin{array}{l}0.105^{* * *} \\
(0.00173)\end{array}$ & $\begin{array}{l}0.0985^{* * *} \\
(0.00173)\end{array}$ \\
\hline $\mathrm{dcp}$ & $\begin{array}{c}-0.0816^{* * *} \\
(0.00248)\end{array}$ & $\begin{array}{r}0.0397 \\
(0.0698)\end{array}$ & $\begin{array}{c}-0.0809^{* * *} \\
(0.00248)\end{array}$ & $\begin{array}{c}-0.0857^{* * *} \\
(0.00247)\end{array}$ \\
\hline demp & $\begin{array}{c}0.595^{* * *} \\
(0.00510)\end{array}$ & $\begin{array}{l}0.692^{* * *} \\
(0.208)\end{array}$ & $\begin{array}{l}0.594^{* * *} \\
(0.00510)\end{array}$ & $\begin{array}{l}0.591^{* * *} \\
(0.00509)\end{array}$ \\
\hline dartcp & $\begin{array}{r}0.0375 \\
(0.0626)\end{array}$ & & $\begin{array}{r}0.0401 \\
(0.0625)\end{array}$ & $\begin{array}{c}0.0452 \\
(0.0629)\end{array}$ \\
\hline dartfun & $\begin{array}{c}-0.228^{* * *} \\
(0.0649)\end{array}$ & & $\begin{array}{c}-0.229^{* * *} \\
(0.0647)\end{array}$ & $\begin{array}{c}-0.225^{* * *} \\
(0.0653)\end{array}$ \\
\hline dartemp & $\begin{array}{l}0.0657 \\
(0.220)\end{array}$ & & $\begin{array}{l}0.0723 \\
(0.219)\end{array}$ & $\begin{array}{l}0.0576 \\
(0.217)\end{array}$ \\
\hline duf1 & $\begin{array}{c}-0.0448^{* * *} \\
(0.00639)\end{array}$ & $\begin{array}{c}-0.0724 \\
(0.196)\end{array}$ & $\begin{array}{c}-0.0461^{* * *} \\
(0.00639)\end{array}$ & $\begin{array}{c}-0.0501^{* * *} \\
(0.00636)\end{array}$ \\
\hline duf2 & $\begin{array}{c}-0.128^{* * *} \\
(0.00857)\end{array}$ & $\begin{array}{c}-0.0258 \\
(0.228)\end{array}$ & $\begin{array}{c}-0.130^{* * *} \\
(0.00857)\end{array}$ & $\begin{array}{c}-0.139^{* * *} \\
(0.00856)\end{array}$ \\
\hline duf3 & $\begin{array}{c}-0.127^{* * *} \\
(0.00521)\end{array}$ & $\begin{array}{l}0.0591 \\
(0.176)\end{array}$ & $\begin{array}{c}-0.129^{* * *} \\
(0.00521)\end{array}$ & $\begin{array}{c}-0.134^{* * *} \\
(0.00519)\end{array}$ \\
\hline duf4 & $\begin{array}{c}-0.0491^{* * *} \\
(0.0114)\end{array}$ & $\begin{array}{r}0.123 \\
(0.250)\end{array}$ & $\begin{array}{c}-0.0507^{* * *} \\
(0.0114)\end{array}$ & $\begin{array}{c}-0.0577^{* * *} \\
(0.0114)\end{array}$ \\
\hline duf5 & $\begin{array}{c}-0.213^{* * *} \\
(0.00418)\end{array}$ & $\begin{array}{r}-0.129 \\
(0.134)\end{array}$ & $\begin{array}{c}-0.215^{* * *} \\
(0.00418)\end{array}$ & $\begin{array}{c}-0.222^{* * *} \\
(0.00416)\end{array}$ \\
\hline duf6 & $\begin{array}{r}-0.0150 \\
(0.00950)\end{array}$ & $\begin{array}{r}0.198 \\
(0.273)\end{array}$ & $\begin{array}{r}-0.0167^{*} \\
(0.00950)\end{array}$ & $\begin{array}{c}-0.0238^{* *} \\
(0.00949)\end{array}$ \\
\hline duf7 & $\begin{array}{c}-0.272^{* * *} \\
(0.00661)\end{array}$ & $\begin{array}{r}0.128 \\
(0.408)\end{array}$ & $\begin{array}{r}-0.273^{* * *} \\
(0.00661)\end{array}$ & $\begin{array}{c}-0.276^{* * *} \\
(0.00659)\end{array}$ \\
\hline duf8 & $\begin{array}{c}-0.568^{* * *} \\
(0.00773)\end{array}$ & $\begin{array}{c}-0.432^{* *} \\
(0.176)\end{array}$ & $\begin{array}{c}-0.569^{* * *} \\
(0.00773)\end{array}$ & $\begin{array}{c}-0.572^{* * *} \\
(0.00770)\end{array}$ \\
\hline duf9 & $\begin{array}{c}-0.690^{* * *} \\
(0.00864)\end{array}$ & $\begin{array}{c}-0.776^{* * *} \\
(0.216)\end{array}$ & $\begin{array}{c}-0.689^{* * *} \\
(0.00863)\end{array}$ & $\begin{array}{c}-0.696^{* * *} \\
(0.00863)\end{array}$ \\
\hline duf10 & $\begin{array}{c}-0.594^{* * *} \\
(0.00439)\end{array}$ & $\begin{array}{c}-0.349^{* * *} \\
(0.129)\end{array}$ & $\begin{array}{c}-0.594^{* * *} \\
(0.00438)\end{array}$ & $\begin{array}{c}-0.598^{* * *} \\
(0.00438)\end{array}$ \\
\hline duf11 & $\begin{array}{c}-0.395^{* * *} \\
(0.00676)\end{array}$ & $\begin{array}{c}-0.430^{* *} \\
(0.183)\end{array}$ & $\begin{array}{c}-0.396^{* * *} \\
(0.00676)\end{array}$ & $\begin{array}{c}-0.399^{* * *} \\
(0.00673)\end{array}$ \\
\hline duf12 & $\begin{array}{c}-0.419^{* * *} \\
(0.00627)\end{array}$ & $\begin{array}{c}-0.376^{* *} \\
(0.160)\end{array}$ & $\begin{array}{r}-0.419^{* * *} \\
(0.00627)\end{array}$ & $\begin{array}{c}-0.424^{* * *} \\
(0.00625)\end{array}$ \\
\hline duf13 & $\begin{array}{r}-0.467^{* * *} \\
(0.00421)\end{array}$ & $\begin{array}{c}-0.410^{* * *} \\
(0.120)\end{array}$ & $\begin{array}{c}-0.467^{* * *} \\
(0.00420)\end{array}$ & $\begin{array}{c}-0.470^{* * *} \\
(0.00420)\end{array}$ \\
\hline duf14 & $\begin{array}{c}-0.402^{* * *} \\
(0.00724)\end{array}$ & $\begin{array}{r}-0.140 \\
(0.261)\end{array}$ & $\begin{array}{c}-0.403^{* * *} \\
(0.00725)\end{array}$ & $\begin{array}{c}-0.406^{* * *} \\
(0.00722)\end{array}$ \\
\hline duf15 & $\begin{array}{c}-0.333^{* * *} \\
(0.00641)\end{array}$ & $\begin{array}{c}-0.329^{*} \\
(0.171)\end{array}$ & $\begin{array}{c}-0.333^{* * *} \\
(0.00641)\end{array}$ & $\begin{array}{c}-0.335^{* * *} \\
(0.00638)\end{array}$ \\
\hline duf16 & $\begin{array}{c}-0.389^{* * *} \\
(0.00344)\end{array}$ & $\begin{array}{c}-0.218^{*} \\
(0.118)\end{array}$ & $\begin{array}{r}-0.389^{* * *} \\
(0.00343)\end{array}$ & $\begin{array}{c}-0.392^{* * *} \\
(0.00342)\end{array}$ \\
\hline
\end{tabular}

Nota: Erros padrões robustos em parêntesis ${ }^{* * *} \mathrm{p}<0,01,{ }^{* *} \mathrm{p}<0,05,{ }^{*} \mathrm{p}<0,1$. Fonte: Resultado da pesquisa. 
Tabela A.6: Regressões completas para os artistas (continuação)

\begin{tabular}{|c|c|c|c|c|}
\hline Var. & $\begin{array}{l}-5 \\
1 \mathrm{w}\end{array}$ & $\begin{array}{l}-6 \\
1 w\end{array}$ & $\begin{array}{l}-7 \\
1 \mathrm{w}\end{array}$ & $\begin{array}{l}-8 \\
\operatorname{lw}\end{array}$ \\
\hline duf17 & $\begin{array}{c}-0.245^{* * *} \\
(0.00295)\end{array}$ & $\begin{array}{c}-0.206^{*} \\
(0.114)\end{array}$ & $\begin{array}{r}-0.245^{* * *} \\
(0.00295)\end{array}$ & $\begin{array}{c}-0.245^{* * *} \\
(0.00294)\end{array}$ \\
\hline duf18 & $\begin{array}{r}-0.207^{* * *} \\
(0.00555)\end{array}$ & $\begin{array}{c}-0.285^{*} \\
(0.163)\end{array}$ & $\begin{array}{c}-0.207^{* * *} \\
(0.00555)\end{array}$ & $\begin{array}{c}-0.208^{* * *} \\
(0.00551)\end{array}$ \\
\hline duf19 & $\begin{array}{c}-0.0729^{* * *} \\
(0.00338)\end{array}$ & $\begin{array}{l}0.0541 \\
(0.103)\end{array}$ & $\begin{array}{c}-0.0730^{* * *} \\
(0.00338)\end{array}$ & $\begin{array}{c}-0.0720^{* * * *} \\
(0.00337)\end{array}$ \\
\hline duf 21 & $\begin{array}{c}-0.150^{* * *} \\
(0.00362)\end{array}$ & $\begin{array}{l}0.0552 \\
(0.113)\end{array}$ & $\begin{array}{c}-0.150^{* * *} \\
(0.00362)\end{array}$ & $\begin{array}{c}-0.151^{* * *} \\
(0.00360)\end{array}$ \\
\hline duf 22 & $\begin{array}{c}-0.0522^{* * *} \\
(0.00426)\end{array}$ & $\begin{array}{l}0.00709 \\
(0.197)\end{array}$ & $\begin{array}{c}-0.0525^{* * *} \\
(0.00425)\end{array}$ & $\begin{array}{l}-0.0522^{* * *} \\
(0.00424)\end{array}$ \\
\hline duf 23 & $\begin{array}{r}-0.157^{* * *} \\
(0.00331)\end{array}$ & $\begin{array}{r}-0.147 \\
(0.101)\end{array}$ & $\begin{array}{c}-0.157^{* * *} \\
(0.00330)\end{array}$ & $\begin{array}{c}-0.158^{* * *} \\
(0.00329)\end{array}$ \\
\hline duf 24 & $\begin{array}{r}-0.141^{* * *} \\
(0.00514)\end{array}$ & $\begin{array}{c}-0.0317 \\
(0.145)\end{array}$ & $\begin{array}{r}-0.142^{* * *} \\
(0.00514)\end{array}$ & $\begin{array}{r}-0.145^{* * *} \\
(0.00511)\end{array}$ \\
\hline $\operatorname{duf} 25$ & $\begin{array}{c}-0.0239^{* * *} \\
(0.00503)\end{array}$ & $\begin{array}{r}0.248 \\
(0.170)\end{array}$ & $\begin{array}{c}-0.0252^{* * *} \\
(0.00503)\end{array}$ & $\begin{array}{l}-0.0268^{* * * *} \\
(0.00501)\end{array}$ \\
\hline duf 26 & $\begin{array}{c}-0.152^{* * *} \\
(0.00378)\end{array}$ & $\begin{array}{l}0.0690 \\
(0.112)\end{array}$ & $\begin{array}{c}-0.153^{* * *} \\
(0.00378)\end{array}$ & $\begin{array}{c}-0.155^{* * *} \\
(0.00376)\end{array}$ \\
\hline $\operatorname{duf} 27$ & $\begin{array}{l}0.221^{* * *} \\
(0.00497)\end{array}$ & $\begin{array}{c}-0.0389 \\
(0.147)\end{array}$ & $\begin{array}{l}0.220^{* * *} \\
(0.00497)\end{array}$ & $\begin{array}{l}0.216^{* * *} \\
(0.00495)\end{array}$ \\
\hline dyr2 & & & & $\begin{array}{l}-0.0721^{* * * *} \\
(0.00285)\end{array}$ \\
\hline dyr3 & & & & $\begin{array}{c}-0.0640^{* * *} \\
(0.00283)\end{array}$ \\
\hline dyr 4 & & & & $\begin{array}{l}-0.0226^{* * *} \\
(0.00288)\end{array}$ \\
\hline dyr 5 & & & & $\begin{array}{l}0.0372^{* * *} \\
(0.00297)\end{array}$ \\
\hline dyr6 & & & & $\begin{array}{l}0.0815^{* * *} \\
(0.00313)\end{array}$ \\
\hline $\mathrm{dco} 2$ & & & & $\begin{array}{l}0.173^{* * *} \\
(0.0207)\end{array}$ \\
\hline dco3 & & & & $\begin{array}{l}0.160^{* * *} \\
(0.0160)\end{array}$ \\
\hline dco 4 & & & & $\begin{array}{l}0.115^{* * *} \\
(0.0127)\end{array}$ \\
\hline dco5 & & & & $\begin{array}{l}0.0832^{* * *} \\
(0.0104)\end{array}$ \\
\hline dco6 & & & & $\begin{array}{l}0.0487^{* * *} \\
(0.00884)\end{array}$ \\
\hline dco7 & & & & $\begin{array}{l}0.0360^{* * *} \\
(0.00776)\end{array}$ \\
\hline $\mathrm{d} \operatorname{co} 8$ & & & & $\begin{array}{l}0.0533^{* * *} \\
(0.00685)\end{array}$ \\
\hline dco 9 & & & & $\begin{array}{l}0.0861^{* * *} \\
(0.00585)\end{array}$ \\
\hline dco10 & & & & $\begin{array}{l}0.0852^{* * *} \\
(0.00463)\end{array}$ \\
\hline dco11 & & & & $\begin{array}{l}0.0276^{* * *} \\
(0.00363)\end{array}$ \\
\hline lambda1 & & & & $\begin{array}{c}-0.279^{* * *} \\
(0.00839)\end{array}$ \\
\hline Constant & $\begin{array}{c}-1.193^{* * *} \\
(0.00819)\end{array}$ & $\begin{array}{c}-0.00699 \\
(0.293)\end{array}$ & $\begin{array}{c}-1.129^{* * *} \\
(0.00830)\end{array}$ & $\begin{array}{c}-1.130^{* * *} \\
(0.0160)\end{array}$ \\
\hline Observations & 937,721 & 1,802 & $1,027,218$ & 937,721 \\
\hline R-squared & 0.460 & 0.174 & & 0.465 \\
\hline
\end{tabular}

Nota: Erros padrões robustos em parêntesis ${ }^{* * *} \mathrm{p}<0,01$, ${ }^{* *} \mathrm{p}<0,05,{ }^{\star} \mathrm{p}<0,1$.

Fonte: Resultado da pesquisa. 